\title{
RESIDENTES EXTRANJEROS Y CRECIMIENTO DEMOGRÁFICO EN EL TERRITORIO ANDALUZ
}

\author{
Carmen Ocaña Ocaña \\ Remedios Larrubia Vargas \\ Departamento de Geografía. Universidad de Málaga \\ rlarrubia@uma.es, carmen.ocana.ocana@gmail.es
}

\section{RESUMEN}

La perspectiva territorial suscita relaciones que amplían la significación de un fenómeno tan importante como el crecimiento de los extranjeros residentes en Andalucía. El objetivo del trabajo es interpretar la forma en que puedan estar afectadas por su presencia las distintas áreas que articulan el territorio andaluz. Se analiza en primer lugar cómo se asientan en su interior, manejando las escalas más expresivas para la comprensión geográfica de su distribución, y en segundo lugar, con esta perspectiva territorial de su distribución, se analizan los efectos sobre las estructuras demográficas y particularmente sobre el crecimiento de las localidades andaluzas.

Palabras clave: Extranjeros, Andalucía, residentes turísticos, sex ratio, rejuvenecimiento.

\begin{abstract}
The territorial perspective highlights relationships that enhance the significance of the important phenomenon of the increase of the number of foreign residents in Andalusia. The purpose of this paper is to interpret how their presence affects the different areas comprising the territory of Andalusia. The manner in which they settle is analyzed first, using the most expressive scales to understand their geographical distribution; secondly, with this territorial perspective of their distribution, the effects on demographic structures are analyzed, in particular the impact on the growth of Andalusian villages and towns.
\end{abstract}

Key words: Foreign residents, Andalusia, tourist residents, sex ratio, rejuvenation.

Fecha de recepción: enero 2011.

Fecha de aceptación: julio 2012. 
A la amplitud de enfoques con los que se ha tratado la inmigración y la población extranjera asentada en España, este trabajo se suma analizando su impacto sobre una región (Andalucía) que hasta 1975 fue territorio de emigrantes, condición que por sus desequilibrios territoriales muchas de sus localidades no han perdido al día de hoy (Sánchez, 1999, Egea, 2005), pero que en la primera década del s. XXI ha acelerado su crecimiento (7,3 millones de habitantes en 2001; 8,3 millones en 2009) bajo el impulso de la inmigración extranjera (Arango, 2004), por lo que puede considerarse un escenario tardío pero significativo de la transición migratoria española (Recaño, 2004).

El objetivo global que se persigue es comprobar en qué medida el territorio andaluz, con su variedad geográfica y sus persistentes desequilibrios territoriales, se ha visto alcanzado por este movimiento inmigratorio, y las posibles diferencias en las formas en que hayan sido afectadas en sus estructuras demográficas o sencillamente en sus crecimientos reales, poblaciones de áreas o localidades dispares geográficamente. El enfoque territorial es así un componente esencial al abordar estos objetivos (Fernández, 2006); de ahí la necesidad de manejar las estadísticas a distintas escalas espaciales, y la alusión repetida a los diferentes ámbitos geográficos en que se articula la región.

\section{CONCENTRACIÓN Y DIFUSIÓN ESPACIAL DE LA POBLACIÓN EXTRANJERA EN ANDALUCÍA}

Por su historial emigratorio, o como ejemplo de «transición migratoria» (Castles, 2009), es relevante que en 2009 se registren en Andalucía 675.180 residentes extranjeros, y que con ellos constituya una pieza más en una de las más representativas de las recientes transformaciones sociales de España (Recher, 2009, Valero, 2006, González, 2005). Por volumen de residentes ocupa el cuarto lugar entre las CCAA españolas, adelantada solo por Madrid, Cataluña y la Comunidad Valenciana, que se han erigido en los escenarios más sólidos de su aglomeración. En términos de tasas, la posición de Andalucía es menos destacable. Con una proporción del $8,1 \%$, se sitúa en el puesto once entre las comunidades. Le adelantan no sólo las tres ya señaladas, con su mayor volumen de residentes extranjeros, sino también otras a las que Andalucía duplica (López, 2006).

El contingente actual es fruto de un crecimiento muy reciente. La presencia de los extranjeros fue siempre reducida, aunque en momentos y lugares haya sido célebre por sus funciones o significados (García, 2002, Urdiales, 2005, IEA, 2002, Nieto, 2002). Sirva de referencia que a 1981 rozaban los 30.000 censados, volumen que hoy encierra más de un municipio andaluz. Es después de 2001 cuando se acelera el crecimiento, alcanzando un registro de 321.570 en el Padrón de 2004. Cifra que se ha duplicado sobradamente en el quinquenio siguiente, originando el volumen al que se ha hecho referencia.

El primer objetivo de este trabajo es analizar el patrón territorial de la distribución que ha surgido tras este crecimiento. La situación que refleja el Padrón a 1 de enero de 2009 es muy expresiva del proceso. Se advierte respecto a pocos años atrás el aumento del número de lugares donde el volumen de los residentes extranjeros es objetivamente importante. Es así que hay más lugares que destacan como centros de residencia de extranjeros, y más extranjeros contenidos en ellos. Pero además, el crecimiento ha ido acompañado de una amplia difusión sobre la casi totalidad del territorio regional. Presencia que con independencia de su cuantía, es geográficamente muy reveladora porque da muestras de la generalizada per- 
meabilidad a su instalación que están ofreciendo espacios rurales sin tradición alguna en este tipo de acogida o con una acreditada trayectoria de emigración y abandono por razones de carácter socioeconómico.

Cuadro 1

DISTRIBUCIÓN PROVINCIAL DE LA POBLACIÓN EN ANDALUCÍA

\begin{tabular}{|l|c|c|c|}
\hline \multicolumn{2}{|c|}{ Residentes extranjeros en Andalucía, distribuidos por provincias } & \multirow{2}{*}{ Población total } \\
\hline Jaén & Número & $\%$ & 669.782 \\
\hline Córdoba & 19.583 & 2,9 & 803.998 \\
\hline Huelva & 24.801 & 3,7 & 513.403 \\
\hline Cádiz & 39.853 & 5,9 & 1.230 .594 \\
\hline Granada & 45.687 & 6,8 & 907.428 \\
\hline Sevilla & 61.732 & 9,1 & 1.900 .224 \\
\hline Almería & 71.993 & 10,7 & 684.426 \\
\hline Málaga & 143.707 & 21,3 & 1.593 .068 \\
\hline \multicolumn{1}{|c|}{ Suma } & 267.824 & 39,7 & 8.302 .923 \\
\hline
\end{tabular}

Fuente: Padrón de habitantes (2009). Elaboración Propia.

En una primera mirada a la región a través de las provincias (cuadro 1) destaca el desequilibrio de la distribución, pues más de la mitad de los extranjeros son residentes de Málaga y Almería. La primacía de ambas provincias hace pensar en el papel que haya podido jugar al efecto el desarrollo turístico o las agriculturas forzadas de cada una de ellas (Izcara, 2003, Izquierdo, 2003, De Miguel, 2005, Jimeno, 2009). Sabido es que estas actividades en ninguno de los dos casos se difunden en todo el territorio provincial, por lo que cabe pensar que los extranjeros tampoco tendrán una distribución regular sobre él. Esta circunstancia invita a un análisis transversal a la división de provincias, siguiendo los ámbitos naturales.

Para este fin, y como unidades intermedias, es bastante satisfactoria por conjugar estructura funcional y ámbitos naturales la referencia espacial de las Unidades Territoriales establecidas por el Plan de Ordenación del Territorio de Andalucía. Son un total de 34, que en los cuadros aparecen ordenadas por sectores geográficos ${ }^{1}$, para conducir la observación también a los grandes ámbitos naturales de Andalucía (Fig. 1).

1 Las que se ubican en Sierra Morena y la cabecera del Guadalquivir, se engloban en el «Sector Montañoso Norte»; como «Guadalquivir» las que ocupan el valle, las campiñas y el borde Subbético funcionalmente muy conectado a ellas; un tercer grupo ordena las depresiones internas de las Béticas (las altiplanicies orientales granadinas y las depresiones de Granada y Antequera) como «Surco Intrabético»; como «Penibética» las de la montaña mediterránea no litoral. Como «Costa», las litorales, y separadamente los Centro regionales (las nueve áreas urbanas andaluzas). 


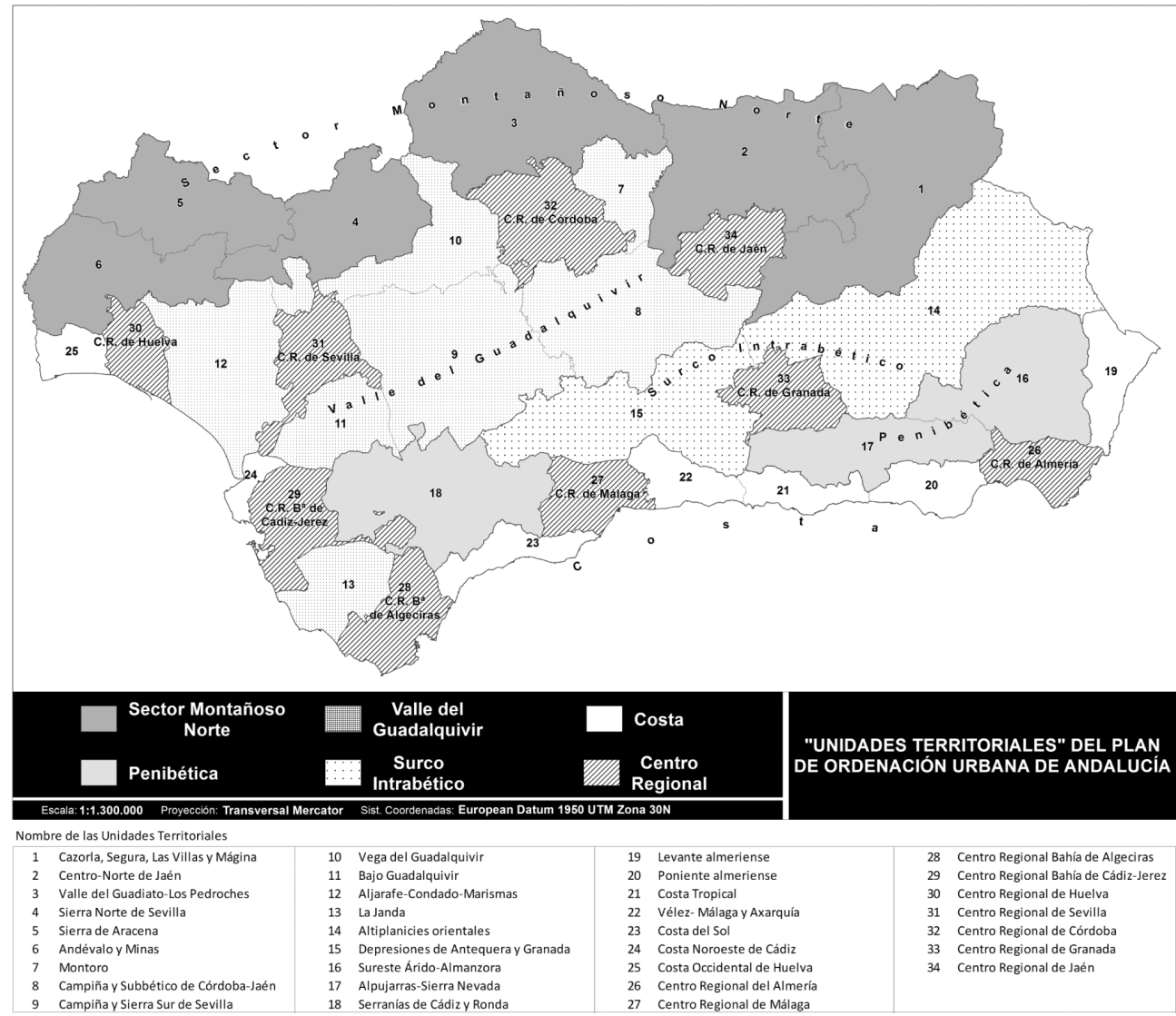

Fuente: Plan de ordenación territorial de Andalucía. Elaboración Propia

Por ámbitos geográficos (cuadro 2) se hace manifiesta la importancia de la Costa, exponente de que conjuga los dos principales factores de atracción que se reflejan en la suma de residentes turísticos por su calidad ambiental, y de trabajadores extranjeros por su dinamismo económico. Se comprueba en estas comarcas importantes niveles de aglomeración. Las «unidades territoriales» costeras acogen a 283.000 extranjeros que residen junto a poco más de 900.000 españoles. A la cabeza, con mucho, el sector pionero del turismo litoral: la Costa del Sol asienta a 1 extranjero por cada 2 españoles, acogiendo más de 120.000 extranjeros. Le sigue el Poniente almeriense, a distancia en volumen, pero igualmente destacables son sus 2 extranjeros por cada cinco españoles. Todo acorde a la impresión derivada de los totales provinciales.

La expectativa de que la costa concentra este fenómeno de asentamiento de extranjeros se confirma rigurosamente (Mazón, 2005, Raya, 2001). Pero se descubre igualmente los abundantes extranjeros que se ubican en las áreas urbanas (Ferrer, 2005). 


\section{Cuadro 2}

\begin{tabular}{|c|c|c|c|c|c|c|c|}
\hline \multicolumn{8}{|c|}{ Tasas de extranjeros en Andalucía por «unidades territoriales» y ámbitos geográficos } \\
\hline \multirow{2}{*}{\multicolumn{2}{|c|}{$\begin{array}{l}\text { Ámbitos } \\
\text { Naturales }\end{array}$}} & \multirow[b]{2}{*}{ Unidades Territoriales (POTA) } & \multicolumn{3}{|c|}{ Población } & \multicolumn{2}{|c|}{ Tasas } \\
\hline & & & \multirow{2}{*}{$\begin{array}{c}\begin{array}{c}\text { Total } \\
\text { (A) }\end{array} \\
141.817 \\
\end{array}$} & \multirow{2}{*}{$\begin{array}{c}\begin{array}{c}\text { Española } \\
\text { (B) }\end{array} \\
137.181 \\
\end{array}$} & \multirow{2}{*}{$\begin{array}{c}\begin{array}{c}\text { Extranj. } \\
\text { (C) }\end{array} \\
4.636 \\
\end{array}$} & \multirow{2}{*}{$\begin{array}{c}\begin{array}{c}\mathrm{C} / \\
(\mathrm{A} / \mathbf{1 0 0})\end{array} \\
3,27 \\
\end{array}$} & \multirow{2}{*}{$\begin{array}{l}\mathbf{B} / \mathbf{C} \\
29,6\end{array}$} \\
\hline \multirow{18}{*}{$\begin{array}{l}\text { 告 } \\
\text { 㪯 } \\
\text { 点 }\end{array}$} & \multirow{6}{*}{ 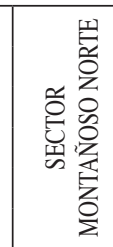 } & Cazorla, Segura, Las Villas y Mágina & & & & & \\
\hline & & Centro-Norte de Jaén & 278.791 & 271.864 & 6.927 & 2,48 & 39,2 \\
\hline & & Valle del Guadiato-Los Pedroches & 82.246 & 80.206 & 2.040 & 2,48 & 39,3 \\
\hline & & Sierra Norte de Sevilla & 33.657 & 32.805 & 852 & 2,53 & 38,5 \\
\hline & & Sierra de Aracena & 39.801 & 38.482 & 1.319 & 3,31 & 29,2 \\
\hline & & Andévalo y Minas & 56.117 & 53.955 & 2.162 & 3,85 & 25,0 \\
\hline & \multirow{7}{*}{ 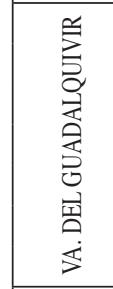 } & Montoro & 40.379 & 39.436 & 943 & 2,34 & 41,8 \\
\hline & & Campiña y Subbético de Córdoba-Jaén & 319.698 & 307.994 & 11.704 & 3,66 & 26,3 \\
\hline & & Campiña y Sierra Sur de Sevilla & 312.379 & 304.323 & 8.056 & 2,58 & 37,8 \\
\hline & & Vega del Guadalquivir & 142.990 & 137.332 & 5.658 & 3,96 & 24,3 \\
\hline & & Bajo Guadalquivir & 147.183 & 144.045 & 3.138 & 2,13 & 45,9 \\
\hline & & Aljarafe-Condado-Marismas & 149.034 & 138.443 & 10.591 & 7,11 & 13,1 \\
\hline & & La Janda & 86.932 & 83.656 & 3.276 & 3,77 & 25,5 \\
\hline & \multirow{2}{*}{ S.I. } & Altiplanicies Orientales & 142.672 & 134.513 & 8.159 & 5,72 & 16,5 \\
\hline & & Depresiones de Antequera y Granada & 198.376 & 186.167 & 12.209 & 6,15 & 15,2 \\
\hline & \multirow{3}{*}{ 㘳苍 } & Sureste árido-Almanzora & 76.584 & 61.348 & 15.236 & 19,89 & 4,0 \\
\hline & & Alpujarras-Sierra Nevada & 64.412 & 59.341 & 5.071 & 7,87 & 11,7 \\
\hline & & Serranías de Cádiz y Ronda & 202.669 & 195.529 & 7.140 & 3,52 & 27,4 \\
\hline \multicolumn{3}{|c|}{ Total «unidades territoriales» interiores } & 2.515 .737 & \begin{tabular}{|l|}
2.406 .620 \\
\end{tabular} & 109.117 & 4,34 & 22,1 \\
\hline \multirow{7}{*}{\multicolumn{2}{|c|}{ 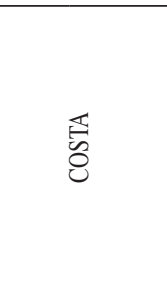 }} & Levante almeriense & 88.803 & 63.305 & 25.498 & 28,71 & 2,5 \\
\hline & & Poniente Almeriense & 242.550 & 172.770 & 69.780 & 28,77 & 2,5 \\
\hline & & Costa de Granada & 127.010 & 108.445 & 18.565 & 14,62 & 5,8 \\
\hline & & Vélez-Málaga y Axarquía & 162.937 & 130.342 & 32.595 & 20,00 & 4,0 \\
\hline & & Costa del Sol & 372.964 & 251.694 & 121.270 & 32,52 & 2,1 \\
\hline & & Costa Noroeste de Cádiz & 119.870 & 117.153 & 2.717 & 2,27 & 43,1 \\
\hline & & Costa Occidental de Huelva & 88.989 & 75.572 & 13.417 & 15,08 & 5,6 \\
\hline \multicolumn{3}{|c|}{ Total «unidades territoriales» Costeras } & 1.203 .123 & 919.281 & 283.842 & 23,59 & 3,2 \\
\hline \multirow{9}{*}{\multicolumn{2}{|c|}{ 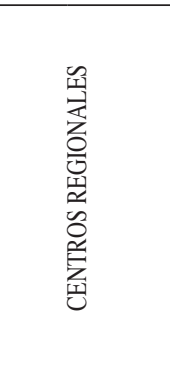 }} & Centro regional de Almería & 247.386 & 216.703 & 30.683 & 12,40 & 7,1 \\
\hline & & Centro regional de Málaga & 863.605 & 762.124 & 101.481 & 11,75 & 7,5 \\
\hline & & Centro regional de Bahía de Algeciras & 263.749 & 242.438 & 21.311 & 8,08 & 11,4 \\
\hline & & Centro regional de Bahía Cádiz-Jerez & 635.836 & 619.348 & 16.488 & 2,59 & 37,6 \\
\hline & & Centro regional de Huelva & 237.977 & 222.965 & 15.012 & 6,31 & 14,9 \\
\hline & & Centro regional de Sevilla & 1.250 .118 & \begin{tabular}{|l|}
1.196 .464 \\
\end{tabular} & 53.654 & 4,29 & 22,3 \\
\hline & & Centro regional de Córdoba & 361.693 & 351.798 & 9.895 & 2,74 & 35,6 \\
\hline & & Centro regional de Granada & 519.161 & 491.690 & 27.471 & 5,29 & 17,9 \\
\hline & & Centro regional de Jaén & 204.538 & 198.312 & 6.226 & 3,04 & 31,9 \\
\hline \multicolumn{3}{|r|}{ Total Centros Regionales } & 4.584 .063 & \begin{tabular}{|l|}
4.301 .842 \\
\end{tabular} & 282.221 & 6,16 & 15,2 \\
\hline \multicolumn{3}{|r|}{ ANDALUCÍA } & 8.302 .923 & 7.627 .743 & 675.180 & 8,13 & 11,3 \\
\hline
\end{tabular}

Fuente: Padrón de habitantes (2009). Elaboración Propia. 
La potencia funcional de las mayores ciudades con sus correspondientes áreas urbanas, es otro factor de acumulación de los extranjeros residentes en Andalucía, aspecto que también se evidencia en otros ámbitos de la geografía española (Pozo, 2009, Bayona, 2008, Fullaondo, 2007). Sobre las «unidades territoriales» de los nueve Centros Regionales andaluces se asienta un volumen de extranjeros muy similar al del ámbito costero (282.221 personas), aunque eso sí, diluidos entre un contingente mucho más numeroso de españoles, ya que estas áreas urbanas concentra el 50\% de la población regional. En consecuencia, con relación a la costa, la tasa de extranjería se rebaja considerablemente. Entre estos Centros Regionales hay diferencias notables, conjunción de su diferente potencia funcional, y de su posición interior o costera. A la cabeza, con clara distancia, aparece la aglomeración malagueña y le sigue, por volumen de extranjeros, el área urbana de Sevilla. A ésta, sin embargo, le adelanta, en cuanto a su peso sobre la población local, el también costero Centro regional de Almería, la única aglomeración urbana en la que los extranjeros alcanzan el 10\% sobre el total de población. Los Centros Regionales de Córdoba y Jaén presentan las aglomeraciones más reducidas.

Entre «unidades territoriales» de la costa y Centros Regionales se cuentan los focos de mayor concentración. Lo que ellos representan sobre el total regional confirma que su distribución en Andalucía implica una fuerte concentración.

Figura 2

\begin{tabular}{|l|}
\hline \multicolumn{1}{|c|}{ Leyenda eje horizontal } \\
$\mathbf{1}^{\circ}$ Costa del Sol \\
$\mathbf{2}^{\circ}$ C.R. de Málaga \\
$\mathbf{3}^{\circ}$ Poniente Almeriense \\
$\mathbf{4}^{\circ}$ C.R. de Sevilla \\
$\mathbf{5}^{\circ}$ Vélez-Málaga y Axarquía \\
$6^{\circ}$ C.R. de Almería \\
$7^{\circ}$ C.R. de Granada \\
$8^{\circ}$ Levante almeriense \\
$9^{\circ}$ C.R. de Bahía de Algeciras \\
$10^{\circ}$ Costa de Granada \\
$11^{\circ}$ C.R. de Bahía Cádiz-Jerez \\
$12^{\circ}$ Sureste árido-Almanzora \\
$13^{\circ}$ C.R. de Huelva \\
$14^{\circ}$ Costa Occidental de Huelva \\
$15^{\circ}$ D. Antequera y Granada \\
$16^{\circ}$ Campiña y Subbético... \\
$17^{\circ}$ Aljarafe-Condado-Marismas \\
$18^{\circ}$ C.R. de Córdoba \\
$19^{\circ}$ Altiplanicies Orientales \\
$20^{\circ}$ Campiña y S Sur de Sevilla \\
$21^{\circ}$ Serranías de Cádiz y Ronda \\
$22^{\circ}$ Centro-Norte de Jaén \\
$23^{\circ}$ C.R. de Jaén \\
$24^{\circ}$ Vega del Guadalquivir \\
$25^{\circ}$ Alpujarras-Sierra Nevada \\
$26^{\circ}$ Cazorla, Segura, Las Villas y Mágina \\
$27^{\circ}$ La Janda \\
$28^{\circ}$ Bajo Guadalquivir \\
$29^{\circ}$ Costa Noroeste de Cádiz \\
$30^{\circ}$ Andévalo y Minas \\
$31^{\circ}$ Valle del Guadiato-Los Pedroches \\
$32^{\circ}$ Sierra de Aracena \\
$33^{\circ}$ Montoro \\
$34^{\circ}$ Sierra Norte de Sevilla \\
\hline
\end{tabular}

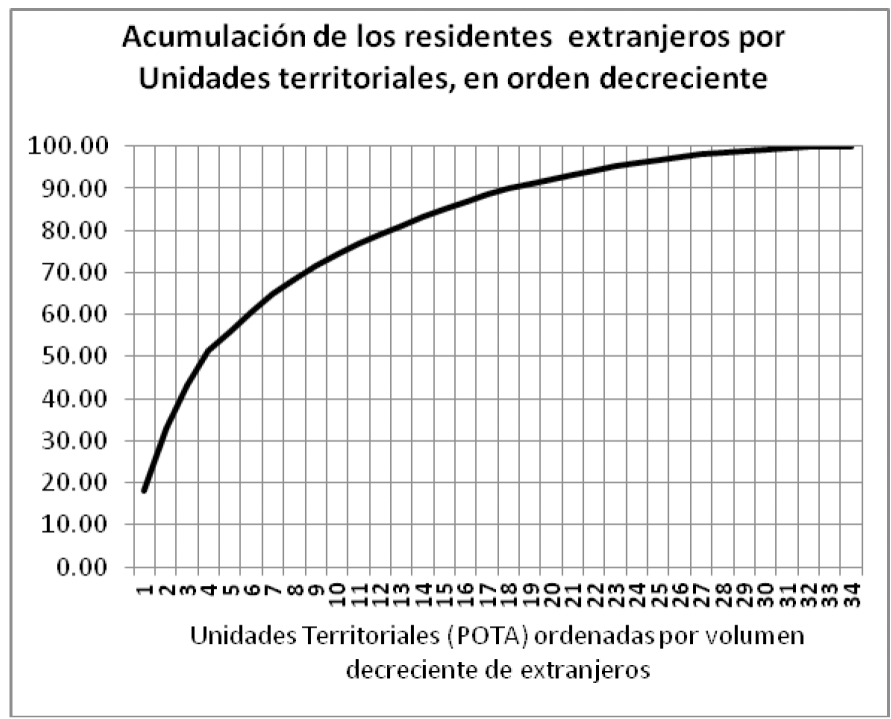

Fuente: Padrón de habitantes (2009). Elaboración Propia. 
Visualmente queda reflejado en la curva de su distribución (Fig. 2). La fuerte pendiente inicial de la curva no deja lugar a duda de la magnitud de unas pocas «unidades territoriales». Con tan sólo las cinco primeras se concentra más del 50\% del total regional; las implicadas sólo confirman lo ya dicho y son en orden a su aportación: $1^{\circ}$ Costa del Sol, $2^{\circ}$ Centro regional de Málaga, $3^{\circ}$ Poniente Almeriense, $4^{\circ}$ Centro regional de Sevilla, $5^{\circ}$ Vélez-Málaga y Axarquía; y con 10 de las 34 ya se contiene el $80 \%$ de los extranjeros empadronados. En consecuencia la curva se hace casi plana en el tramo medio y final. En estas posiciones se sitúan las unidades del interior y sólo se deslizan entre ellas dos Centros Regionales, interiores igualmente (el de Córdoba y el de Jaén) y también la Costa Noroeste de Cádiz que constituye una excepción dentro de su ámbito.

Un recuento básico de los municipios refuerza las apreciaciones anteriores. Observando la cifra de extranjeros empadronados, de 770 municipios tan sólo seis no cuentan con algún residente extranjero, muestra evidente de la permeabilidad a su asentamiento. Y también, rotundamente, confirma la concentración de su distribución. La curva de distribución entre los municipios se presenta en la figura 3. Como refuerzo a lo que ya evidencia la gráfica pueden retenerse estas dos anotaciones: por un extremo, el que 260 municipios con menor número de extranjeros acogen en total a poco más de 6.000. Por otro, que la mitad de los extranjeros (340.000) estén registrados en solo 15 municipios que son los de mayor aglomeración. En orden decreciente: Málaga (43.253) Marbella (36.585), Sevilla (34.679), Mijas (30.011), Ejido (El) (29.746), Roquetas de Mar (25.806), Fuengirola (25.259) seguidos por Almería, Benalmádena, Estepona, Torremolinos, Granada, Níjar, Córdoba y Vélez-Málaga.

Figura 3

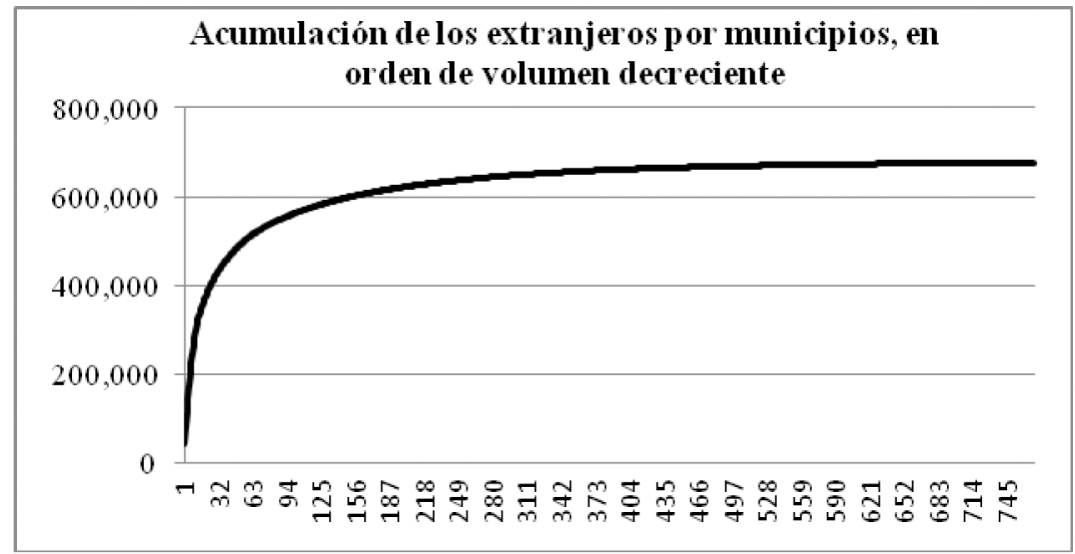

Fuente: Padrón de habitantes (2009). Elaboración Propia.

Vistas las localizaciones de las concentraciones mayores, puede deducirse el papel del espacio interior. Apenas 110.000 extranjeros para un vasto territorio, menos poblado, eso sí, que los ámbitos anteriores, pero no obstante con 2,5 millones de habitantes.

Su difuminada distribución sobre este ámbito permite enfatizar en el segundo rasgo de la distribución de los extranjeros en la región: la amplia difusión espacial, con una efectiva 
presencia en todos los ámbitos espaciales y en todas las escalas del sistema urbano, por constituir un hecho poco visible pero de interés geográfico particular (sea por su posible incidencia en la dinámica demográfica, sea por lo que significa de involución de sus modelos migratorios). Difusión que se concreta en su presencia en la mayor parte de los municipios. Cierto que en cantidades generalmente muy reducidas, pero de significado muy variable de acuerdo a la propia dimensión de los asentamientos. Por ello, para valorar este fenómeno es conveniente modificar la escala de observación y entrar en el detalle de los municipios y sus volúmenes demográficos. Pues en orden a describir esta otra faceta, es conveniente atender más a las tasas que a los volúmenes absolutos.

Volumen efectivo y peso en el total de población son dos estrategias de observar la distribución. La primera es muy eficiente para describir los rangos de las aglomeraciones. La segunda es más propicia para valorar su impacto en las poblaciones. Es evidente que las dos perspectivas son complementarias y necesarias para una región con un sistema de asentamientos tan rico y dispar en tamaños, proclive a menospreciar, con la sola perspectiva del volumen, grupos extranjeros que pueden por el contrario tener significación en el contexto de la población local. Incidiendo en esta idea, se han representado los municipios clasificados en virtud de sus tasas (Fig. 4) o en virtud de sus efectivos (Fig. 5), indicando el número de municipios y el número de extranjeros en cada uno de los casos. Cada una de las distribuciones da una lectura diferente. Al compararlas, destaca, por ejemplo, el número importante de municipios con tasas por encima del $20 \%$ (Fig. 4) a pesar de que son pocos los que reúnen más de 5.000 o 10.000 residentes extranjeros (Fig. 5).

Figura 4

DISTRIBUCIÓN POR MUNICIPIOS, SEGÚN LA TASA DE EXTRANJEROS DEL MUNICIPIO

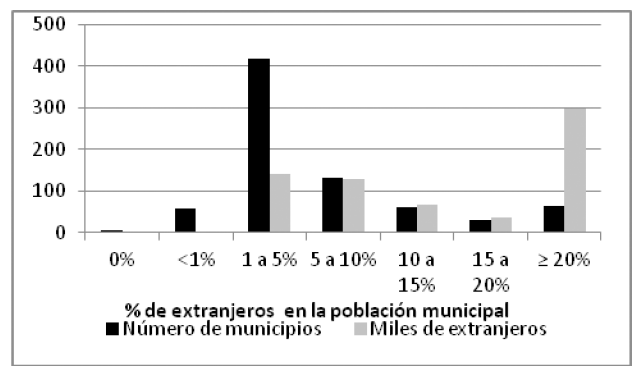

Fuente: Padrón de habitantes (2009). Elaboración propia.
Figura 5

DISTRIBUCIÓN POR MUNICIPIOS, SEGÚN EL VOLUMEN DE EXTRANJEROS RESIDENTES

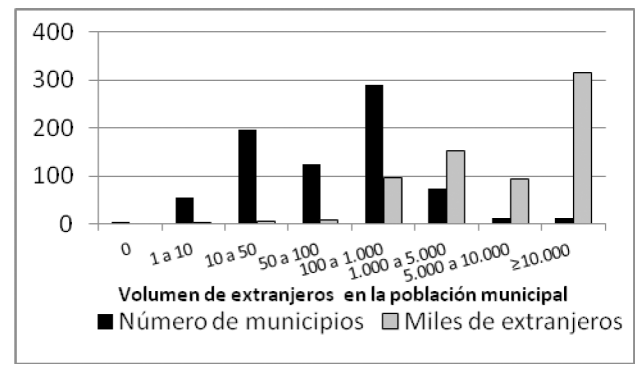

Fuente: Padrón de habitantes (2009). Elaboración propia.

El desajuste entre tasas y volúmenes viene determinado por la abundancia de municipios de cualquier rango o tamaño demográfico. De donde se deriva que a esta escala municipal, contingentes no cuantiosos signifiquen localmente tasas muy significativas, del mismo modo que en las ciudades de mayor tamaño, las capitales, por ejemplo, con volúmenes generalmente elevados de residentes extranjeros, sea excepcional una tasa del 10\%, que la ofrece únicamente Almería. Pueblos como Canillas o Sedella de la Axarquía malagueña, con 200 a 300 extranjeros tienen tasas por encima del 37\%, y en el extremo contrario, Sevilla, el tercer 
Cuadro 3

NÚMERO DE MUNICIPIOS SEGÚN VOLUMEN DE POBLACIÓN Y\% DE EXTRANJEROS

\begin{tabular}{|c|c|c|c|c|c|c|c|}
\hline \multirow[b]{2}{*}{$\begin{array}{c}\% \text { de } \\
\text { Extranjeros }\end{array}$} & \multicolumn{6}{|c|}{ Municipios según número de habitantes } & \multirow{2}{*}{$\begin{array}{l}\text { Sumas de } \\
\text { filas }\end{array}$} \\
\hline & $<500$ & $500-1000$ & $1000-5000$ & $\begin{array}{r}5000- \\
20000\end{array}$ & $\begin{array}{l}20.000- \\
100.000\end{array}$ & $>100.000$ & \\
\hline 0 & 5 & 1 & & & & & 6 \\
\hline$<1 \%$ & 12 & 4 & 33 & 8 & 0 & 0 & 57 \\
\hline 1 a $5 \%$ & 41 & 47 & 172 & 121 & 32 & 6 & 419 \\
\hline 5 a $10 \%$ & 16 & 21 & 53 & 24 & 15 & 4 & 133 \\
\hline 10 a $15 \%$ & 11 & 11 & 24 & 9 & 6 & 1 & 62 \\
\hline 15 a $20 \%$ & 4 & 2 & 13 & 6 & 4 & 0 & 29 \\
\hline \multirow[t]{2}{*}{$>20 \%$} & 7 & 8 & 25 & 12 & 11 & 1 & 64 \\
\hline & 96 & 94 & 320 & 180 & 68 & 12 & 770 \\
\hline
\end{tabular}

Fuente: Padrón de habitantes (2009). Elaboración propia.

Cuadro 4

CLASIFICACIÓN DE LOS NIVELES DE «INCIDENCIA»DE LA POBLACIÓN EXTRANJERA EN LOS MUNICIPIOS

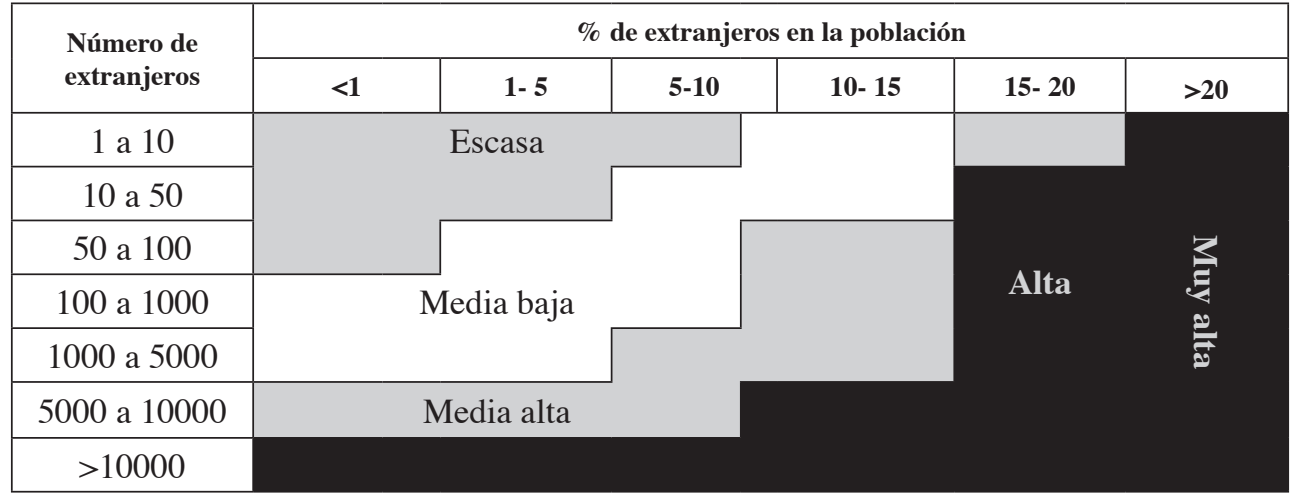

Fuente: Padrón de habitantes (2009). Elaboración Propia.

municipio de Andalucía en volumen de extranjeros (casi 35.000 residentes) tiene una tasa menor de $5 \%{ }^{2}$.

Centrándose en la escala municipal, si se distribuyen los municipios en razón de sus tasas y de su rango de tamaño demográfico (cuadro 3), se hace manifiesto que hay tasas signifi-

2 Habría de puntualizarse que estas débiles tasas medias de las capitales no son un correcto reflejo del impacto de estas poblaciones en el espacio urbano, pues debido al carácter de mosaico social que tiene la ciudad, hay áreas interiores de concentración notable. Una fracción del 25 al 30\% de los extranjeros residentes en ciudades como Málaga, Sevilla o Almería, conviven en áreas donde su proporción se eleva por encima del 15\% de la población. 
cativas entre los más pequeños, cuya importancia al valorar la distribución del fenómeno se diluye debido a que seguramente se producen a partir de contingentes débiles. Como la finalidad es perfilar mejor la distribución de los municipios de mayor o menor incidencia, se ha recurrido a establecer unas categorías que pudieran denominarse de incidencia o relevancia local, adoptando las dos ópticas. Se han distinguido cinco rangos (denominados: de incidencia «escasa», «media-baja», «media-alta», «alta» y «muy alta») de acuerdo a los umbrales del diagrama del cuadro 4 .

Figura 6

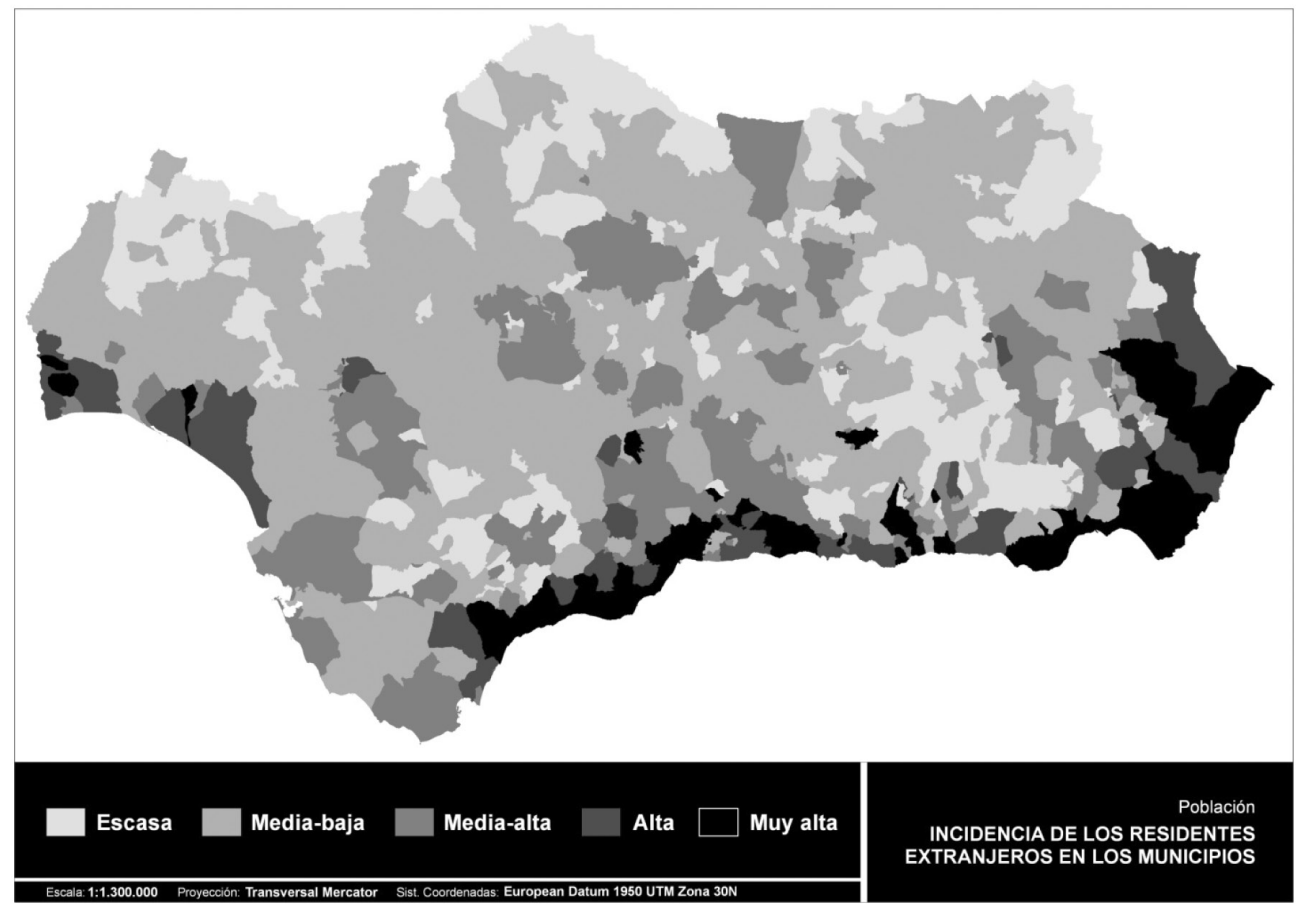

Fuente: Padrón de habitantes (2009). Elaboración Propia.

La distribución espacial de estos resultados se ha llevado a una representación cartográfica (Fig. 6). Aunque problemas de escala no permiten una apreciación detallada, resulta muy efectiva para afianzar la imagen territorial de la importante concentración costera y la extensa difusión interior. Pero para una mayor concreción, en el cuadro 5 se ha mostrado el número de municipios que dentro de cada Unidad Territorial se clasifican en cada nivel de incidencia.

Estos datos aportan matices a la impresión de conjunto de la distribución espacial obtenida en atención al volumen. Con ellos damos por cerrada la descripción del modelo de su distribución territorial.

Lo esencial no se modifica: confirma que las áreas de muy alta y alta incidencia se concentran en la Costa, como cabía esperar por el volumen, pero se atenúa su inclusión en los 
Cuadro 5

INCIDENCIA DE LA POBLACIÓN EXTRANJERA (MUNICIPIOS POR «UNIDADES TERRITORIALES»)

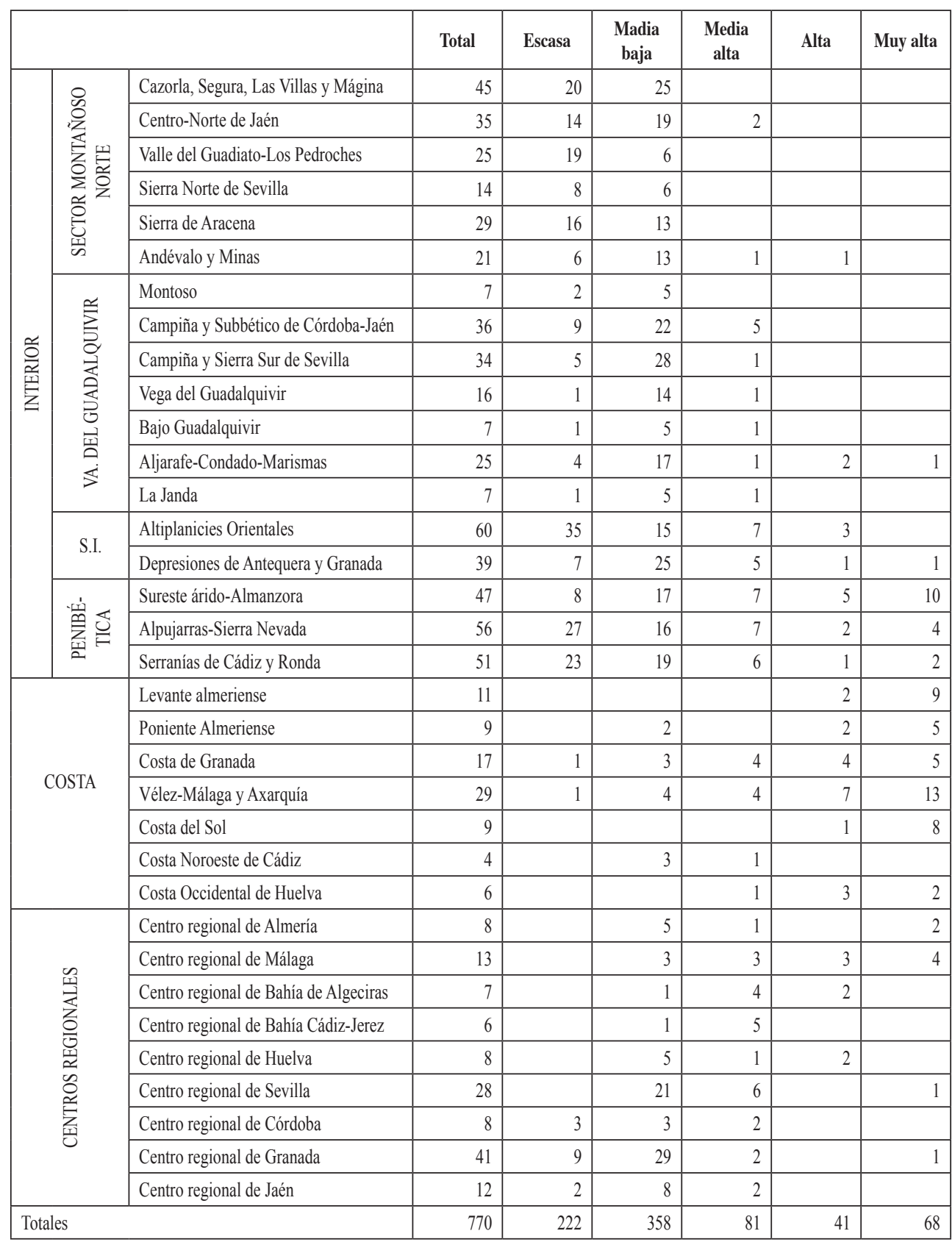

Fuente: Padrón de habitantes (2009). Elaboración Propia. 
Centro regionales, a no ser los litorales. Pero sobre todo muestra otro trazo que se escapaba en la perspectiva anterior: al continuo espacial donde la incidencia es elevada, esencialmente costero, se incorporan diversos municipios del espacio de la Penibética, es decir, las montañas meridionales próximas al litoral.

Además, con esta perspectiva se confirma la amplitud espacial de los municipios en que los extranjeros tienen cierto significado, si no por su volumen, sí por unas tasas modestas pero significativas. El bloque amplísimo de los 358 municipios con incidencia media-baja cubre con bastante regularidad todo el interior, incluidos Centro regionales como Sevilla y Granada, como bien queda patente en el mapa.

\section{LOS EFECTOS SOBRE LAS ESTRUCTURAS Y EL CRECIMIENTO DEMOGRÁFICO}

El segundo objetivo, tras conocer su distribución, es indagar sobre el efecto que las migraciones hayan podido ejercer en la evolución demográfica de las poblaciones en que se asientan, resolviéndose éste como uno de los aspectos más retirado en una somera ojeada a la bibliografía inmigratoria (Izquierdo, 2003, Pozo, 2009, Olivera, 2005, Fernández, 2004, 2009 , etc). El punto de vista cambia. Se trata de observar su distribución en términos de contribución a las estructuras demográficas y al crecimiento real, en combinación con el resto de los residentes.

El análisis se orienta a la comprobación de su diferente repercusión entre localidades o sectores del territorio andaluz.

El interés por esta puntualización se hace manifiesto al relacionar el patrón territorial de la distribución de los extranjeros, con los contrastes en la trayectoria demográfica de los municipios y comarcas andaluzas pues se comprueba cómo su presencia coincide también con ámbitos o localidades con trayectorias demográficas de declive (Fernández, 2001, AA.VV., 1998, Arroyo, 1998, Carvajal, 1993, Ocaña, 1999, Nieto, 2005). Que su presencia haya podido espolear el crecimiento en las áreas urbanas o litorales, en las que alcanzan mayor concentración, es una hipótesis bastante segura, pero está por comprobar si su difuminada presencia ha ejercido de contención efectiva del declive demográfico de muchos otros municipios, en los que con menores volúmenes también se han hecho presentes (Collate, 2006).

Se hará una incursión primero en los efectos que haya generado sobre las estructuras demográficas, por su potencial incidencia en la perspectivas de las poblaciones, para centrarse luego en constatar la incidencia ya ejercida sobre el crecimiento: la forma en que han contribuido al crecimiento real de este quinquenio, y la importante reducción de localidades que gracias a los extranjeros han contenido su declive. A este fin se adopta de referencia temporal el quinquenio 2004-2009 previo al momento del análisis de la distribución.

\section{Los efectos sobre la estructura demográfica}

También los caracteres de las estructuras demográficas en lo que a edad y sexo se refiere se han modificado bajo el peso creciente de la población extranjera. En esta línea, hay que decir que la bibliografía que se ha ocupado de la selectividad migratoria pone de manifiesto que en todas las migraciones libres se produce selectividas por edad y sexo, eso sí, diferen- 
tes según el tipo de inmigración (Arango, 2004, Carvajal, 2009). Sobre el conjunto de la población española cabe destacar cómo ha acrecentado el peso relativo del estrato de población en edades activas jóvenes, de donde se deriva un leve freno en el incremento del peso de los mayores (Fernández, 2004, 2009). También, en cuanto a la sex ratio, el importante desequilibrio masculino en la composición por sexo de los extranjeros - que la progresiva feminización de las migraciones no llega a corregir - tiene sobre la estructura media española un efecto compensador, pues corrige débilmente su déficit femenino, aunque este efecto concreto es variable de región a región (Fig. 7), en función de los grupos asentados y debido a la amplia diferencia en el grado de feminización de las migraciones según origen.

Figura 7

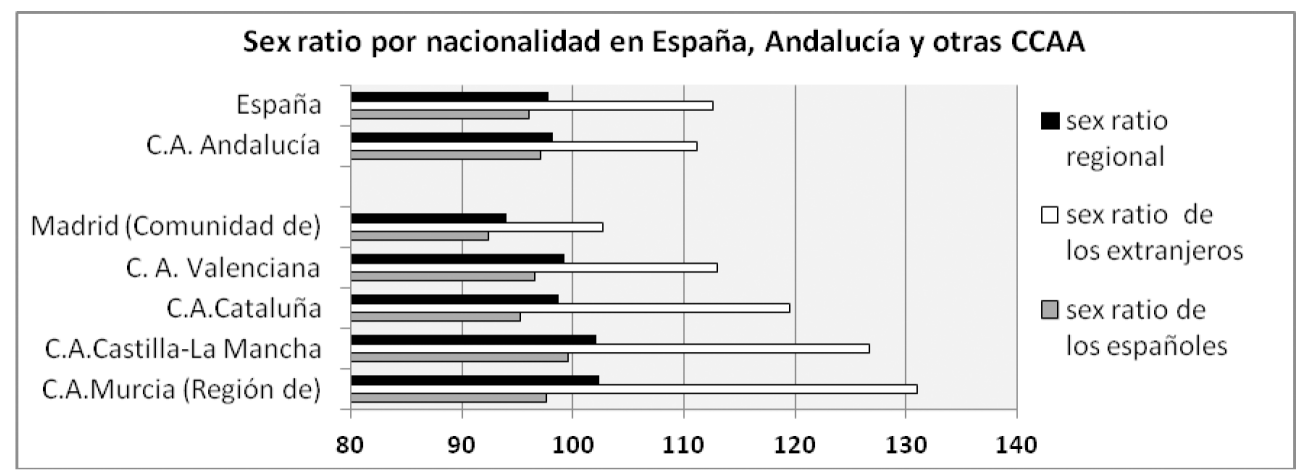

Fuente: Padrón de habitantes (2009). Elaboración Propia.

En Andalucía se advierten efectos similares a los de la media española, tanto en el refuerzo de los jóvenes activos, como en la nivelación de la sex ratio, pero las diferencias existentes dentro de la región en la estructura de los extranjeros asentados y los contrastes estructurales entre las poblaciones andaluzas, permiten intuir diferencias importantes en su interior, que se intentan poner de manifiesto mediante el análisis de la estructura de edad y sexo de ambos colectivos, en sus diferentes ámbitos.

\section{A) Efectos sobre la sex ratio}

El sesgo masculino de la sex ratio de los extranjeros se traduce en Andalucía en un modesto efecto positivo en el equilibrio de su estructura entre sexos (cuadro 6). La moderación del efecto se debe en primer lugar al propio volumen de los extranjeros y, significativamente a que este colectivo sea en Andalucía más equilibrado que en otras regiones, e incluya una proporción muy importante de mujeres.

Sin embargo, el análisis intrarregional muestra contrastes importantes. La variación en el peso de las mujeres entre la población extranjera, la clave en estas diferencias intrarregionales, está asociada a dos características territoriales: una es la composición por origen de la población asentada (pues igual que se reconoce a nivel español, la feminización de las migraciones es diferente según orígenes, y es más alta entre las de origen americano, que africano, por ejem- 
Cuadro 6

ANDALUCÍA. COMPOSICIÓN POR SEXO DE LOS COLECTIVOS ESPAÑOL Y EXTRANJERO

\begin{tabular}{|c|c|c|c|c|c|c|c|c|}
\hline \multicolumn{3}{|c}{ Hombres y mujeres extranjeros } & \multicolumn{3}{c|}{ Hombres y mujeres españoles } & \multicolumn{2}{c|}{ Hombres y mujeres en Andalucía } \\
\hline Extranjeros & Extranjeras & $\begin{array}{c}\text { Sex ratio } \\
\text { extranjeros }\end{array}$ & Españoles & Españolas & $\begin{array}{c}\text { Sex ratio } \\
\text { españoles }\end{array}$ & $\begin{array}{c}\text { Total } \\
\text { Hombres }\end{array}$ & $\begin{array}{c}\text { Total } \\
\text { Mujeres }\end{array}$ & $\begin{array}{c}\text { Sex ratio en } \\
\text { Andalucía }\end{array}$ \\
\hline 355.473 & 319.707 & 111,2 & 3.757 .910 & 3.869 .833 & 97,1 & 4.189 .540 & 4.113 .383 & 98,2 \\
\hline
\end{tabular}

Fuente: Padrón de habitantes (2009). Elaboración Propia.

plo) (Cárdenas, 2008, Marcu 2009) y otra, es relativa a las características de los mercados de trabajo de las localidades, fundamentalmente por el papel de los servicios, que absorben a más mujeres, o por ciertas especializaciones de las actividades agrarias, debido a la asociación que han ido generando con algunos colectivos específicos (Catarino, 2000; Gordo, 2002).

Las actividades de servicios son un factor esencial en la distribución de las mujeres extranjeras. Por grandes ámbitos geográficos, la relación entre las actividades de servicios y la sex ratio de los extranjeros asentados queda perfectamente reflejada en los Centros Regionales, donde la sex ratio de los extranjeros es casi equilibrada, con diferencias muy notables respecto a los otros ámbitos, por lo que su efecto corrector sobre el sesgo femenino de las sex ratios urbanas es lógicamente muy reducido. El hecho recuerda la alta participación de las trabajadoras extranjeras en los servicios personales y del hogar, que frecuentemente deriva a este equilibrio mayor de la sex ratio de los extranjeros en las ciudades (Cuadro 7).

Cuadro 7

SEX RATIOS POR GRANDES ÁMBITOS GEOGRÁFICOS

\begin{tabular}{|l|r|c|r|r|r|r|r|}
\hline \multirow{2}{*}{} & \multicolumn{2}{|c|}{ Población Total } & \multicolumn{2}{c|}{ Residentes extranjeros } & \multicolumn{3}{c|}{ Sex Ratio } \\
\cline { 2 - 8 } & \multicolumn{1}{c|}{ Hombres } & \multicolumn{1}{c|}{ Mujeres } & \multicolumn{1}{c|}{ Hombres } & \multicolumn{1}{c|}{ Mujeres } & \multicolumn{1}{c|}{ Total } & Extranjeros & \multicolumn{1}{c|}{ Españoles } \\
\hline Sierras del Norte & 314.908 & 317.521 & 10.357 & 7.579 & 99,2 & 136,7 & 98,3 \\
\hline Guadalquivir & 600.472 & 598.123 & 23.142 & 20.224 & 100,4 & 114,4 & 99,9 \\
\hline Surco Intrabético & 171.515 & 169.533 & 11.336 & 9.032 & 101,2 & 125,5 & 99,8 \\
\hline Zona Penibética & 173.564 & 170.101 & 14.499 & 12.948 & 102,0 & 112,0 & 101,2 \\
\hline Costa & 611.565 & 591.558 & 152.453 & 131.389 & 103,4 & 116,0 & 99,8 \\
\hline Centros Regionales & 2.241 .359 & 2.342 .704 & 143.686 & 138.535 & 95,7 & 103,7 & 95,2 \\
\hline Andalucía & 4.113 .383 & 4.189 .540 & 355.473 & 319.707 & 98,2 & 111,2 & 97,1 \\
\hline
\end{tabular}

Fuente: Padrón de habitantes (2009). Elaboración Propia.

El efecto de los servicios se hace presente también en el sector costero, especialmente si se desciende en el análisis a las «unidades territoriales» (cuadro 8). Los contrastes que se advierten entre sus «unidades territoriales» se pueden interpretar en clave de la importancia relativa de sus funciones turísticas o agrarias. Basta comparar las cifras de la costa almeriense u onubense, con la malagueña. 
Cuadro 8

SEX RATIOS POR «UNIDADES TERRITORIALES»

\begin{tabular}{|c|c|c|c|c|c|}
\hline & & & Sex Total & $\begin{array}{c}\text { Sex } \\
\text { Extranjeros }\end{array}$ & Sex Españoles \\
\hline \multirow{18}{*}{$\begin{array}{l}\text { 旁 } \\
\text { 离 } \\
\text { 乙 }\end{array}$} & \multirow{6}{*}{ 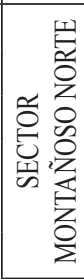 } & Cazorla, Segura, Las Villas y Mágina & 102,2 & 204,6 & 100,0 \\
\hline & & Centro-Norte de Jaén & 98,5 & 127,7 & 97,9 \\
\hline & & Valle del Guadiato-Los Pedroches & 96,8 & 122,0 & 96,2 \\
\hline & & Sierra Norte de Sevilla & 100,3 & 100,9 & 100,2 \\
\hline & & Sierra de Aracena & 100,1 & 133,0 & 99,1 \\
\hline & & Andévalo y Minas & 97,1 & 95,5 & 97,1 \\
\hline & \multirow{7}{*}{ 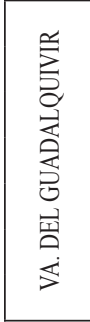 } & Montoso & 100,3 & 146,9 & 99,4 \\
\hline & & Campiña y Subbético de Córdoba-Jaén & 99,4 & 128,6 & 98,4 \\
\hline & & Campiña y Sierra Sur de Sevilla & 99,9 & 110,6 & 99,6 \\
\hline & & Vega del Guadalquivir & 100,7 & 121,9 & 99,9 \\
\hline & & Bajo Guadalquivir & 101,6 & 110,3 & 101,4 \\
\hline & & Aljarafe-Condado-Marismas & 101,0 & 103,6 & 100,8 \\
\hline & & La Janda & 102,4 & 98,2 & 102,6 \\
\hline & \multirow{2}{*}{ S.I. } & Altiplanicies Orientales & 101,8 & 132,8 & 100,2 \\
\hline & & Depresiones de Antequera y Granada & 100,7 & 120,9 & 99,5 \\
\hline & \multirow{3}{*}{ 兽导 } & Sureste árido-Almanzora & 105,3 & 118,0 & 102,4 \\
\hline & & Alpujarras-Sierra Nevada & 103,2 & 115,5 & 102,3 \\
\hline & & Serranías de Cádiz y Ronda & 100,5 & 98,0 & 100,6 \\
\hline \multirow{7}{*}{\multicolumn{2}{|c|}{$\begin{array}{l}\overleftrightarrow{\xi} \\
0 \\
\delta\end{array}$}} & Levante almeriense & 105,8 & 119,8 & 100,7 \\
\hline & & Poniente Almeriense & 114,4 & 158,3 & 100,7 \\
\hline & & Costa de Granada & 100,7 & 114,7 & 98,5 \\
\hline & & Vélez-Málaga y Axarquía & 101,1 & 102,0 & 100,9 \\
\hline & & Costa del Sol & 99,0 & 100,1 & 98,4 \\
\hline & & Costa Noroeste de Cádiz & 100,2 & 101,4 & 100,1 \\
\hline & & Costa Occidental de Huelva & 103,9 & 122,4 & 101,0 \\
\hline \multirow{9}{*}{\multicolumn{2}{|c|}{ 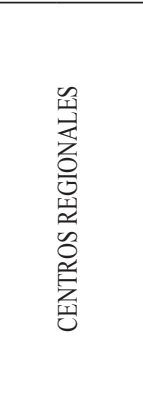 }} & Centro regional de Almería & 99,5 & 133,2 & 95,5 \\
\hline & & Centro regional de Málaga & 95,8 & 101,2 & 95,1 \\
\hline & & Centro regional de Bahía de Algeciras & 99,7 & 119,0 & 98,1 \\
\hline & & Centro regional de Bahía Cádiz-Jerez & 96,3 & 89,8 & 96,5 \\
\hline & & Centro regional de Huelva & 96,4 & 97,8 & 96,3 \\
\hline & & Centro regional de Sevilla & 94,4 & 93,4 & 94,4 \\
\hline & & Centro regional de Córdoba & 93,8 & 89,9 & 93,9 \\
\hline & & Centro regional de Granada & 94,9 & 109,9 & 94,1 \\
\hline & & Centro regional de Jaén & 96,2 & 115,8 & 95,6 \\
\hline \multicolumn{3}{|r|}{ ANDALUCÍA } & 98,2 & 111,2 & 97,1 \\
\hline
\end{tabular}

Fuente: Padrón de habitantes (2009). Elaboración Propia. 
Son muy significativas las que oponen el Poniente Almeriense y la Costa del Sol. En El Poniente, la sex ratio se dispara por el perfil muy definido de los extranjeros (es zona de predominio de trabajadores africanos, con alta participación de subsaharianos varones) que se traduce en una alta sex ratio positiva. En la Costa del Sol, el colectivo extranjero es muy equilibrado, aspecto a que contribuye su carácter funcional (actividades turísticas) y el peso de los residenciales turísticos extranjeros.

A escala de «unidades territoriales» se percibe que en muchas de ellas se acentúa el habitual predominio masculino de los extranjeros. Ocurre en áreas geográficas tan diferentes como las zonas litorales agrícolas ya mencionadas (Levante y Poniente Almeriense, o costa occidental de Huelva) o zonas del interior y montañosas, como se aprecia en la Sierra de Cazorla, Segura, Las Villas y Mágina, y en algunos de los Centros Regionales como Almería o Jaén. Tras esta distribución, aparentemente aleatoria, se trasluce el predominio de algunos colectivos y su asociación con determinadas especializaciones agrarias. Así, en ámbitos olivareros de Jaén (Martínez, 2004), y naturalmente en el litoral de agricultura intensiva (Sempere, 2002), el peso mayor de los grupos de nacionalidades africanas que son los que presentan las sex ratios de predominio masculino más acusadas, particularmente si de subsaharianos se trata, acrecientan el desequilibrio a favor de los varones, en un efecto contrario al señalado en las áreas urbanas.

Si la observación desciende a los municipios, los contrastes entre las localidades llegan a ser muy acusados, y no siempre con un patrón territorial definido. En su justificación se reconocen no sólo las diferencias hasta aquí apuntadas (grupo de origen, mercado de trabajo) sino también la particular superposición entre la estructura demográfica heredada de las etapas emigratorias y las que incorporan los aportes extranjeros recientes. A corta distancia, por ejemplo entre la montaña inmediata y la zona litoral mediterránea, se aprecia como pueblos hasta hace poco emisores que acumularon un sesgo masculino en la sex ratio de la población española, con los aportes extranjeros recientes, en unos casos han compensado el desequilibrio anterior -hecho habitual si han sido alcanzados por la actividad turística- o, por el contrario, cuando es la actividad agrícola la que anima los municipios, han acrecentado el desequilibrio masculino.

La casuística desborda el espacio de este trabajo, pero como expresión de ella se presenta en un cuadro resumen la clasificación de los municipios por la forma en que se han visto afectados en su sex ratio (cuadro 9).

De estos datos cabe resaltar dos observaciones. La primera es que la incidencia en la sex ratio general es insignificante en muchos municipios (un total de 296), a lo que habría que añadir como dato muy importante, que en ellos se recoge más de la mitad de la población de Andalucía, lo cual está en consonancia con la modestia del efecto sobre la población regional en su conjunto, antes indicado. La segunda, es que entre los municipios que efectivamente están afectados, su efecto más frecuente es la acentuación de la sex ratio positiva (se comprueba sobre 242 municipios). Circunstancia que se justifica por dos hechos: uno, la abundancia de localidades rurales que a causa de la emigración vienen arrastrado una sex ratio positiva (generalmente de valor débil) y otro, que fuera de las áreas urbanas o turísticas, es mucho más acentuado que en la media regional el predominio de los hombres en el colectivo extranjero. 
Cuadro 9

MUNICIPIOS SEGÚN SU SEX RATIO Y EL MODO EN QUE ESTÁ AFECTADA POR LA SEX RATIO DE LOS EXTRANJEROS

\begin{tabular}{|l|r|r|r|r|r|}
\hline \multirow{2}{*}{$\begin{array}{c}\text { Tipo de sex ratio } \\
\text { del conjunto de la } \\
\text { población }\end{array}$} & \multicolumn{5}{|c|}{ Tipo de efecto de los extranjeros en la sex ratio general } \\
\cline { 2 - 6 } \multicolumn{1}{c|}{ Sin efecto } & $\begin{array}{c}\text { Equilibrar o } \\
\text { contrarrestar }\end{array}$ & $\begin{array}{c}\text { Reforzar el } \\
\text { déficit }\end{array}$ & $\begin{array}{c}\text { Invertir el } \\
\text { déficit }\end{array}$ & \multicolumn{1}{c|}{ Suma } \\
\hline Equilibrada & 86 & 50 & & & 136 \\
\hline Déficit de mujeres & 131 & 69 & 242 & 13 & 455 \\
\hline Déficit de varones & 79 & 66 & 33 & 1 & 179 \\
\hline Suma & 296 & 185 & 275 & 14 & 770 \\
\hline
\end{tabular}

Fuente: Padrón de habitantes (2009). Elaboración Propia.

\section{B) Efectos sobre la estructura de edad de las poblaciones andaluzas}

El efecto generalmente más valorado es el rejuvenecimiento que pueda desprenderse por la incorporación de una proporción elevada de adultos jóvenes.

Para intuir el efecto de rejuvenecimiento que pueden aportar a la población andaluza, basta observar el contraste existente entre las pirámides del colectivo extranjero y del español dentro de Andalucía (Fig. 8 y 9). Sumando ambas pirámides se reconoce el efecto real en la pirámide de edad de la población andaluza, muy similar al de la media española, como se puede observar en las respectivas pirámides compuestas por ambos colectivos (Fig. 10 y 11), aunque con incidecia más débil por su tasa más baja de extranjería.

La cuestión es si este efecto es genérico a todas las poblaciones y consecuentemente moderado en todas ellas, o si sus diferencias locales se traducen también en efectos de mayor intensidad.

Figura 8

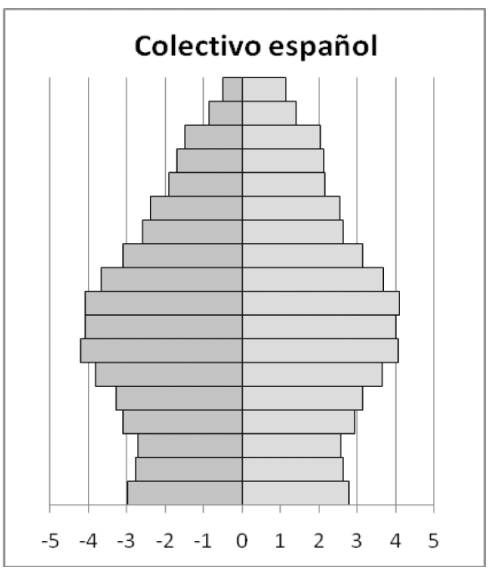

Figura 9

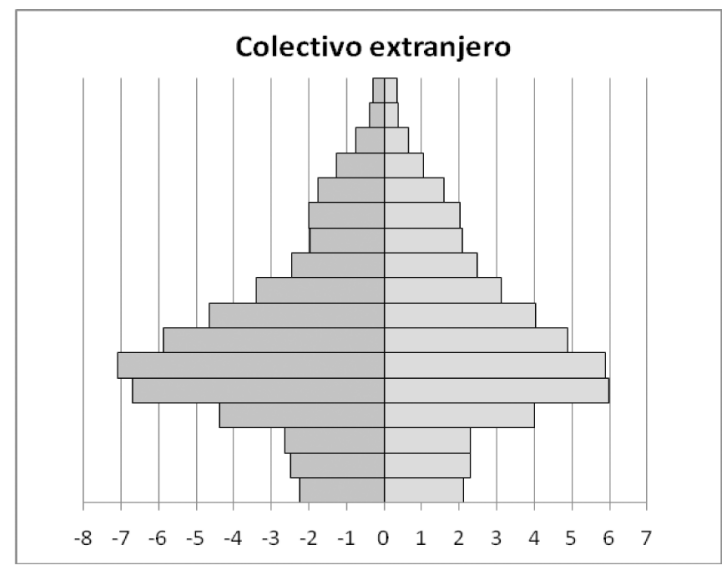

Fuente: Padrón de habitantes (2009). Elaboración Propia. 
Figura 10

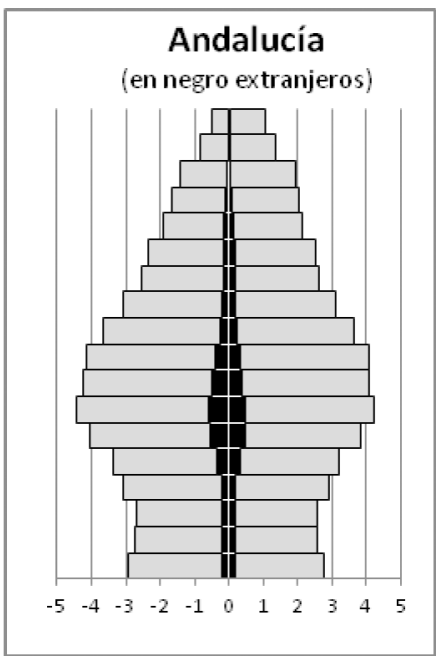

Figura 11

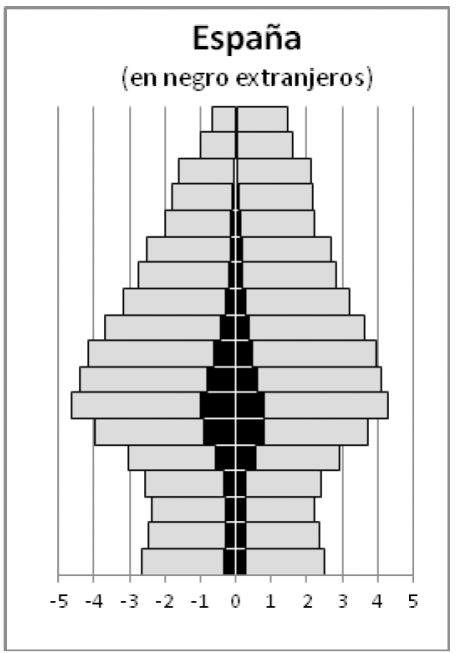

Fuente: Padrón de habitantes (2009). Elaboración Propia.

Esta observación se efectúa a través de la comparación de las medias de edad de extranjeros y españoles, a diferentes escalas de su territorio.

Observando los contrastes espaciales, se advierte que las diferencias fundamentales entre la población española reflejan el diferente nivel de envejecimiento de los lugares en relación con la trayectoria demográfica precedente. Por el contrario, las existentes entre los extranjeros tienen su raíz en las diferentes estructuras por origen que se puede apreciar entre unas localidades y otras, y más genéricamente en los modelos migratorios que están en el origen de sus asentamientos (Larrubia, 2011).

Puede decirse que los contrastes más importantes en la media de edad de residentes extranjeros se justifican por la existencia de dos modelos migratorios, «los que vienen a trabajar y los que vienen a descansar» (López, 1995) como base de sus actuales asentamientos: el relacionado con el residencial turístico y el relacionado con la migración económica. Difieren, como es natural, en otros muchos caracteres sociales, pero en relación con el tema en cuestión, les opone un potente contraste en la estructura de edad. Por edad del flujo migratorio en primer lugar, y también por años de estancia, los extranjeros relacionados al residencial turístico difieren, por su envejecimiento, de los grupos asentados por las oleadas recientes de inmigración económica, en general jóvenes. A título de ejemplo las figuras 12 y 13 representan la pirámide de los residentes andaluces de nacionalidad alemana y de nacionalidad rumana, escogidos como ejemplos paradigmáticos de uno y otro modelo.

Cada uno de estos modelos tiene patrones propios en la distribución espacial sobre la región, y aunque se entrecruzan ocasionalmente y de modo muy frecuente en los espacios costeros, son la causa más genérica de las diferencias espaciales en la juventud de los extranjeros andaluces.

Para una primera impresión de estas diferencias territoriales, las Fig. 14 y 15 presentan las existentes a nivel de los grandes ámbitos geográficos. A esta escala ya se advierte la par- 
Figura 12

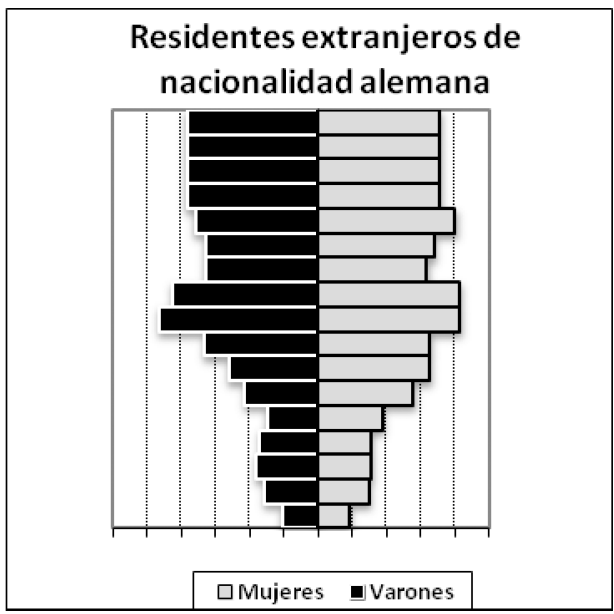

Figura 13

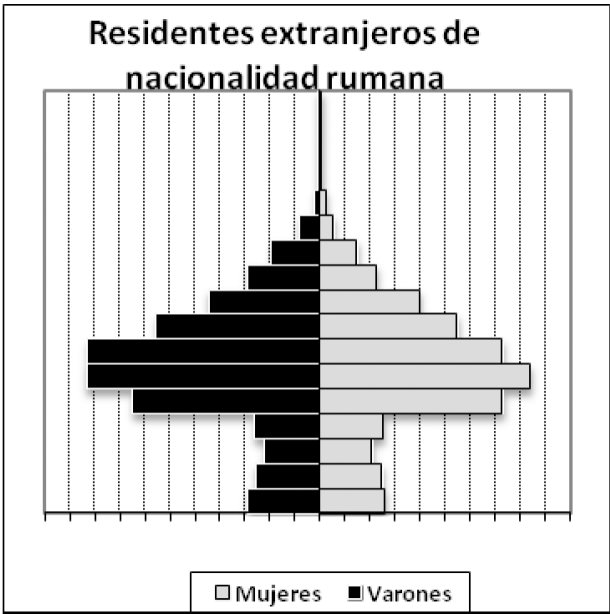

Fuente: Padrón de habitantes (2009). Larrubia (2011)

ticularidad de dos de ellos, la Penibética y la Costa. El primero (Fig. 14) muestra que en la zona Penibética, la edad de los extranjeros no difiere de la media de edad de los españoles, aunque ésta no es precisamente joven; mientras en la Costa, donde la población española es más joven, los extranjeros ofrecen una media de edad más elevada. Peculiaridad que se hace sentir sobre la estructura de edad del total de población de ambos espacios (Fig. 15). Así, frente a la regularidad con la que los distintos ámbitos reproducen el efecto de leve rejuvenecimiento que se experimenta en el conjunto de Andalucía, se hace visible que éste casi se anula en la Penibética, o se invierte, actuando de leve envejecimiento en la Costa.

Figura 14

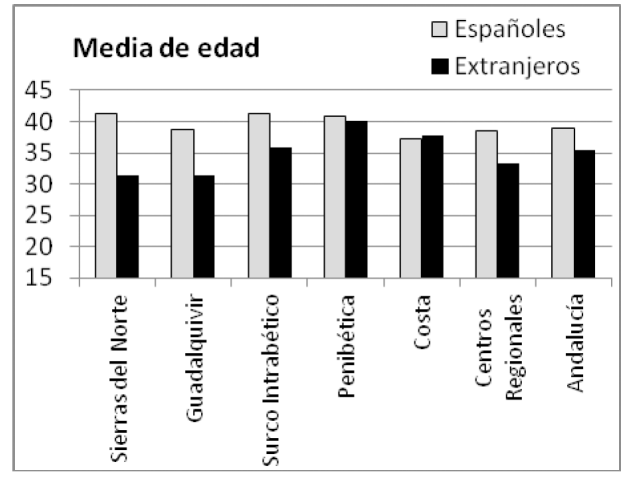

Fuente: Padrón de habitantes (2009). Elaboración Propia.
Figura 15

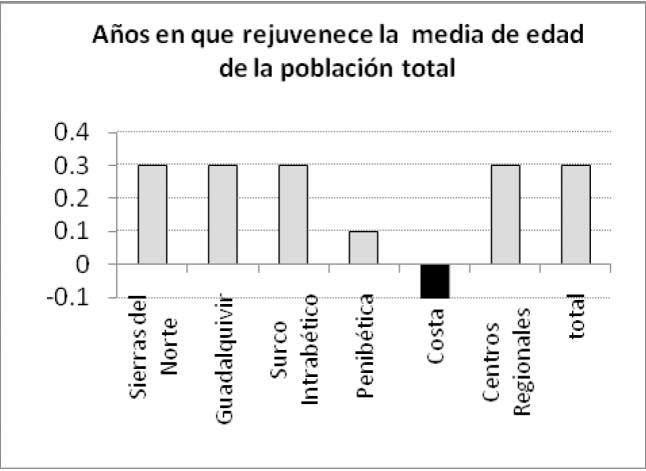

Fuente: Padrón de habitantes (2009). Elaboración Propia 
Figura 16

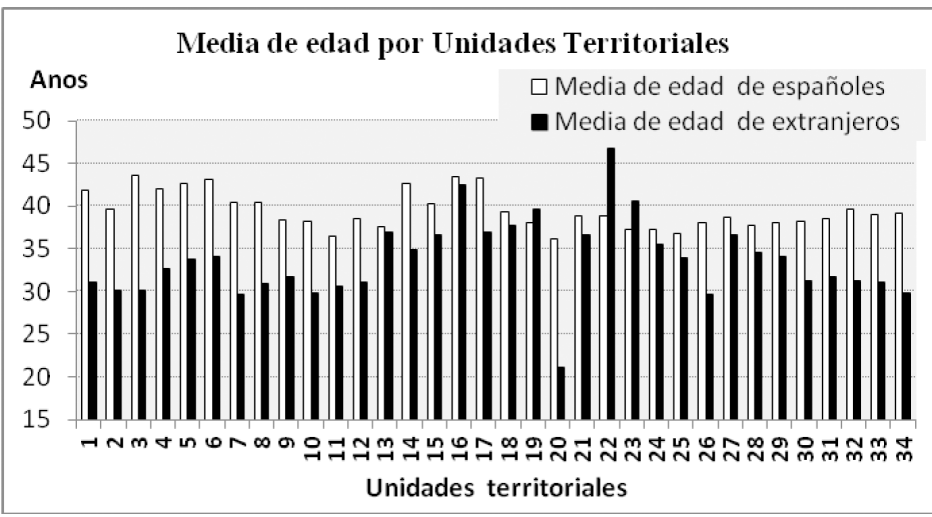

Fuente: Padrón de habitantes (2009). Elaboración Propia.

Figura 17

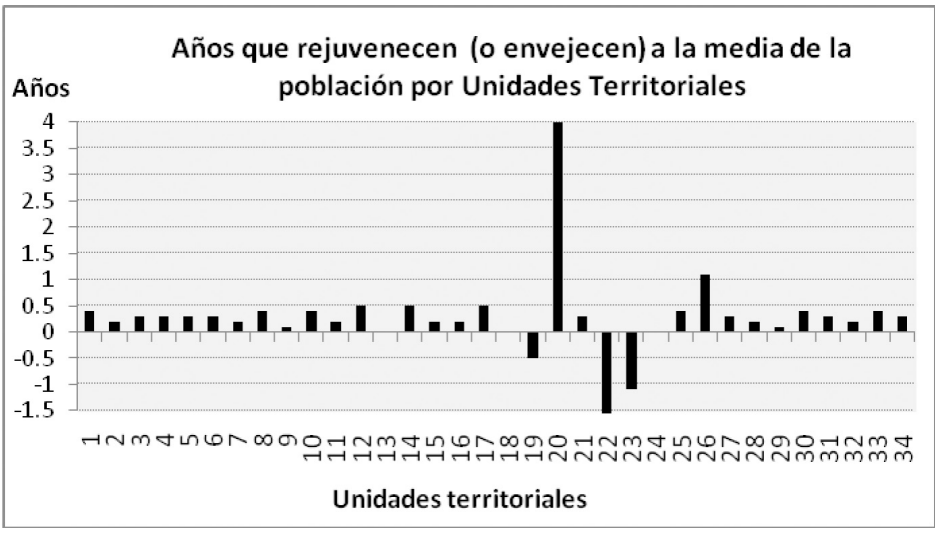

Fuente: Padrón de habitantes (2009). Elaboración Propia.

\begin{tabular}{|l|}
\hline Leyenda eje horizontal \\
\hline 1. Cazorla, Segura, Las... \\
\hline 2. Centro-Norte de Jaén \\
\hline 3. V. Guadiato-Los Pedroches \\
\hline 4. Sierra Norte de Sevilla \\
\hline 5. Sierra de Aracena \\
\hline 6. Andévalo y Minas \\
\hline 7. Montoso \\
\hline 8. Campiña y Subbético de... \\
\hline 9.Campiña y Sierra S. Sevilla \\
\hline 10.Vega del Guadalquivir \\
\hline 11.Bajo Guadalquivir \\
\hline 12. Aljarafe -Condado-Maris. \\
\hline 13.La Janda \\
\hline 14. Altiplanicies Orientales \\
\hline 15. D. Antequera y Granada \\
\hline 16. Sureste árido-Almanzora \\
\hline 17. Alpujarras-Sierra Nevada \\
\hline 18. S. de Cádiz y Ronda \\
\hline 19. Levante almeriense \\
\hline 20.Poniente Almeriense \\
\hline 21.Costa de Granada \\
\hline 22.Vélez-Málaga y Axarquía \\
\hline 23.Costa del Sol \\
\hline 24.Costa Noroeste de Cádiz \\
\hline 25. Costa Occ. De Huelva \\
\hline 26.C.R. de Almería \\
\hline 27.C.R. de Málaga \\
\hline 28.C.R. de B. de Algeciras \\
\hline 29.C.R. de Bahía Cádiz-Jerez \\
\hline 30.C.R. de Huelva \\
\hline 31.C.R. de Sevilla \\
\hline 32.C.R. de Córdoba \\
\hline 33.C.R. de Granada \\
\hline 34.C.R. de Jaén \\
\hline
\end{tabular}

Al descender la observación a las «unidades territoriales», como siempre, los contrastes son más acentuados. Se han recogido en las figuras 16 y 17. Sobre ellas cabe destacar, por un lado, que son varias las unidades en las que los extranjeros son de edad media más elevada que los españoles, y por otro, por sobresalir entre todas, la extraordinaria juventud de los extranjeros en la unidad del Poniente Almeriense. En consecuencia puede constatarse (Fig. 17) que eleva en más de un año la edad media de la población de Vélez-Málaga y Axarquía o de la Costa del Sol, y por el contrario reporta un rejuvenecimiento de más de un año a la población del Centro Regional de Almería, y hasta cuatro a la del Poniente Almeriense. 
Naturalmente estos perfiles se hacen más definidos al observar los contrastes a nivel de municipios, ${ }^{3} \mathrm{y}$ es a este nivel donde se puede apreciar mejor el alcance de uno de los fenómenos más singulares, o contrario a la pauta normal: que los extranjeros envejezcan la media de edad de la población local.

Incidiendo en este hecho, se puede precisar que confirmando la heterogeneidad de los asentamientos extranjeros en Andalucía, sobre 65 de sus municipios este colectivo tiene media de edad de 45 años y más (más de 50, con mucha frecuencia), por lo que no cabe esperar que estas localidades se rejuvenezcan con su presencia. En cuanto a la distribución, unos pocos se dispersan aisladamente en distintos ámbitos geográficos, generalmente de montaña ( 2 en el Andévalo, 2 en Cazorla, 3 en la Sierra Sur de Sevilla), o con más frecuencia en el Surco Intrabético (9 municipios); pero lo más sobresaliente es su abundancia sobre la Costa (mediterránea) y la Penibética. Sobre estas zonas se asientan 49 de los 65.

Su presencia va unida a tres escenarios diferentes. La de núcleos jóvenes y dinámicos que se envejecen algo por su presencia, que es muy común en los municipios costeros y turísti$\cos$; la que corresponde a municipios de poca población española todavía joven, donde derivan a un envejecimiento notable, que es un escenario más excepcional (Arboleas en Almería sería un ejemplo extremo, pero se repite a menos intensidad por el Levante Almeriense). Y con mucha más frecuencia, la superposición de los extranjeros mayores con poblaciones españolas igual o más envejecidas, especialmente frecuente en el reborde montañoso de los sectores costeros mediterráneos. Su propia similitud no les hace modificar de manera muy sensible la estructura media, pero reafirma el envejecimiento de las poblaciones.

\section{Los extranjeros en el crecimiento de las poblaciones}

El crecimiento de la población española viene siendo el efecto demográfico más inmediato del aumento de los residentes extranjeros, y de manera indirecta, también a través de la natalidad se han convertido en factor de crecimiento (Pozo, 2009, Izquierdo, 2003, López, 2006; Fernández, 2006).

Ambos efectos se advierten en Andalucía con cierta entidad. Una mirada al conjunto de la población regional muestra lo esperado, cómo el aumento de los extranjeros ha operado positivamente en el crecimiento total. Para recalcar esta evidencia, se presenta gráficamente lo diferente que hubiera sido el crecimiento en estos años de no contar con su contribución (Fig. 18). E igual que a nivel español, también se ha percibido el aumento de la natalidad por efecto de la inmigración extranjera. Sirvan de refrendo, aunque sólo sea gráfico, los siguientes dos comprobantes: la muy llamativa diferencia existente en las tasas bruta de natalidad del colectivo extranjero y los residentes españoles (Fig. 19) en la que se suma diferencias en fecundidad especialmente en las edades de los colectivos, y el efecto de este hecho en la suave mejora de la tasa bruta regional, superior a la que se derivaría de la sola población española (Fig. 20).

3 Un recuento básico así lo confirma. En la observación de los municipios, se comprueba también la mayor juventud del colectivo extranjero: se cumple en 587 municipios de los 739 de los que se dispone de la información; frente a unos 83 en que son de más edad. Y en unos 100 municipios el efecto es apreciables: en 50 rebaja en un año la edad media local, y en otros 17 lo hace en cuantía más alta. Y en sentido contrario también se cuentan 19 municipios donde los extranjeros provocan un envejecimiento de más de un año de media. 
Figura 18

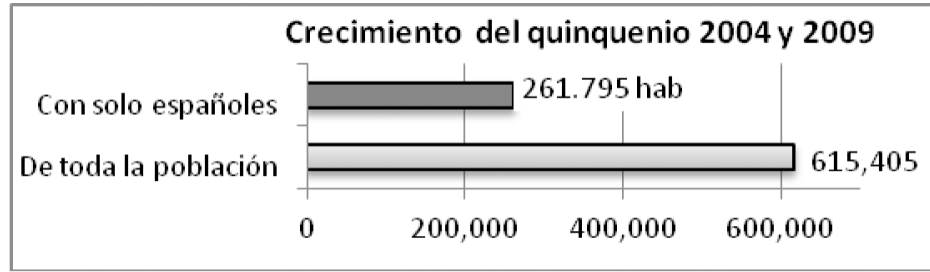

Fuente. Padrón de habitantes de 2004 y 2009. Elaboración Propia

Figura 19

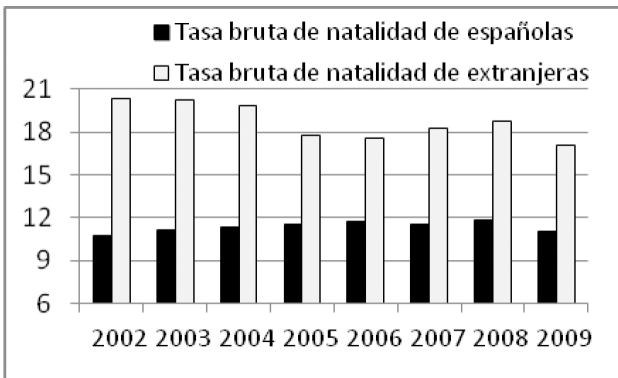

Fuente. Padrón de habitantes de 2002 y 2009. Elaboración Propia
Figura 20

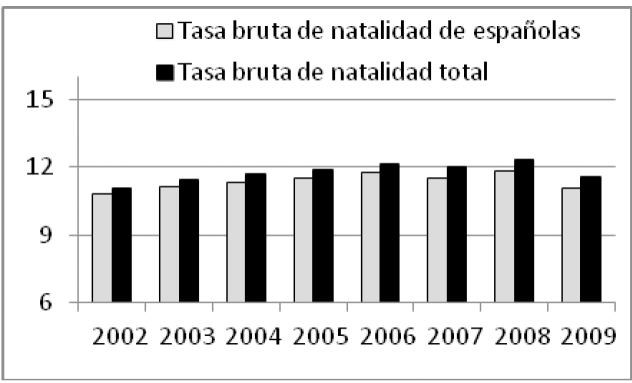

Fuente. Padrón de habitantes de 2002 y 2009. Elaboración Propia

Apuntado el efecto positivo en el crecimiento de la población regional, el objetivo es constatar hasta dónde se difunde espacialmente, y qué tipo de localidades han sido las más afectadas. Teniendo en cuenta la distribución irregular de los extranjeros, y las diferencias existentes en los ritmos de crecimiento de las poblaciones, se puede prever un cuadro muy complejo.

El acercamiento a esta posible diversidad se ha realizado a través del análisis de la composición del crecimiento real de la población, comparando la contribución al mismo de extranjeros y españoles, en el quinquenio 2004-2009 (el quinquenio de mayor crecimiento y previo a la fecha en que se ha analizado la actual distribución). El resultado ha mostrado un cuadro de situaciones tan variado como cabía esperar. Para reducirlo a su sentido más esencial, se han tipificado unas situaciones básicas, en las que salvo nueve municipios, se han podido clasificar los 764 restantes:

- Una situación muy común (tipo 1) es que el descenso de la población española, a pesar de estar acompañada del crecimiento de la extranjera, arrastre al descenso real de la población local. Ocurre en 245 municipios.

- b) Otra situación menos extendida, pero de gran interés (tipo 2), es aquella en que aumenta el volumen de la población local, aún perdiendo población española, gracias a que el aumento de los extranjeros compensa y supera esa pérdida. La reproducen 133 municipios. 
- c) La más común de las situaciones es la que suma el crecimiento de ambos grupos (tipo 3). A ella responden 388 municipios. Esta situación resulta poco perfilada si no se hace intervenir la participación en el crecimiento de cada uno de ellos. Por este motivo se ha analizado dividida en tres subtipos, en orden a la aportación de los extranjeros.

Cuadro 10

MUNICIPIOS POR CRECIMIENTO ENTRE 2004 Y 2009 Y SU RELACIÓN CON LOS EXTRANJEROS

\begin{tabular}{|c|c|c|c|c|c|c|c|c|}
\hline \multirow{2}{*}{\multicolumn{2}{|c|}{$\begin{array}{l}\text { Combinación de extranjeros y españoles en el } \\
\text { crecimiento }\end{array}$}} & \multicolumn{6}{|c|}{ Municipios por volumen de habitantes } & \multirow{2}{*}{ Total } \\
\hline & & $<500$ & $\begin{array}{c}500- \\
1.000\end{array}$ & $\begin{array}{l}1.000 \\
5.000\end{array}$ & $\begin{array}{l}5.000- \\
20.000\end{array}$ & $\begin{array}{l}20.000- \\
100.000\end{array}$ & $>100.000$ & \\
\hline \multicolumn{2}{|c|}{$\begin{array}{l}\text { Tipo 1. Decrecen; aunque crecen los } \\
\text { extranjeros }\end{array}$} & 49 & 47 & 125 & 21 & 0 & 3 & 245 \\
\hline \multicolumn{2}{|c|}{$\begin{array}{l}\text { Tipo 2. Crecen gracias al incremento de } \\
\text { los extranjeros }\end{array}$} & 11 & 17 & 75 & 25 & 3 & 2 & 133 \\
\hline \multirow{3}{*}{$\begin{array}{l}\text { Tipo } 3 \text {. Crecen } \\
\text { ambos colectivos }\end{array}$} & $\begin{array}{l}\text { Tipo } 3.1 \text { Extranjeros: } \\
\text { < } 20 \% \text { del C.R. }\end{array}$ & 9 & 3 & 24 & 41 & 9 & 2 & 88 \\
\hline & $\begin{array}{l}\text { Tipo 3.2. Extranjeros: } \\
20 \text { a 50\% del C.R. }\end{array}$ & 9 & 11 & 34 & 53 & 25 & 1 & 133 \\
\hline & $\begin{array}{l}\text { Tipo 3.3. Extranjeros: } \\
<50 \% \text { del C.R. }\end{array}$ & 13 & 15 & 60 & 39 & 31 & 4 & 162 \\
\hline \multicolumn{2}{|l|}{ No clasificados } & 5 & 1 & 2 & 1 & 0 & 0 & 9 \\
\hline \multicolumn{2}{|c|}{ Todos los municipios } & 96 & 94 & 320 & 180 & 68 & 12 & 770 \\
\hline
\end{tabular}

Fuente. Padrón de habitantes de 2002 y 2009. Elaboración Propia

El cuadro 10 recoge el resultado de la asignación de cada municipio en uno de estos modelos. Se presentan atendiendo también al rango demográfico del municipio, para dilucidar su posible dependencia del tamaño de la red de asentamientos. Efectivamente hay coherencia: los pueblos pequeños (en realidad municipios de poca población) absorben la situación de declive; igual que los de tamaño de 20.000 a 100.000 habitantes (soportes normalmente de ciudades medias) se distribuyen en el tercer «tipo».

Sin desdeñar la relación entre los tipos reconocidos y los rangos demográficos de los municipios, se puede adelantar que sólo en su contexto de distribución territorial cobran su verdadero sentido.

Para rescatar la perspectiva territorial, el análisis municipal se reinserta a continuación dentro de los marcos de las «unidades territoriales». Se combinarán dos acercamientos: el de la Unidad Territorial como conjunto demográfico, y el de la variabilidad interna de sus poblaciones (cuadro 11 y cuadro 12). 
Cuadro 11

CRECIMIENTO DE LA POBLACIÓN ENTRE 2004 Y 2009 POR «UNIDADES TERRITORIALES»

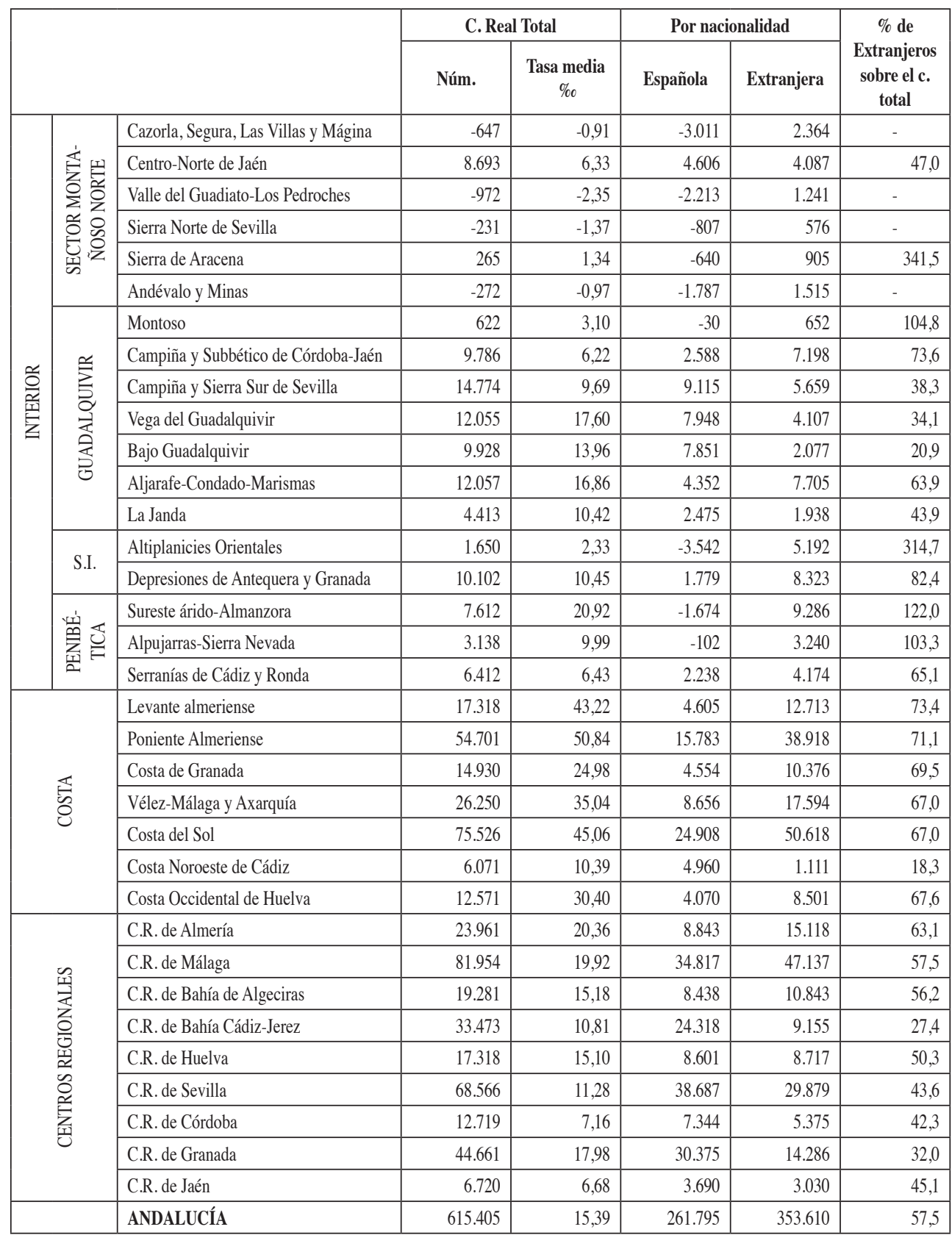

Fuente: Padrón de habitantes (2004 y 2009). Elaboración Propia. 
Cuadro12 $2^{4}$

PROPORCIÓN DE MUNICIPIOS DE LAS «UNIDADES TERRITORIALES» EN CADA «TIPO»DE CRECIMIENTO5

\begin{tabular}{|c|c|c|c|c|c|c|c|c|}
\hline & & & Tipo 1 & Tipo 2 & Tipo 3.1 & Tipo 3.2 & Tipo 3.3 & Suma \\
\hline \multirow{18}{*}{$\begin{array}{l}\text { 잉 } \\
\text { 孚 } \\
\text { 穵 }\end{array}$} & \multirow{6}{*}{ 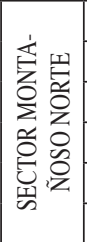 } & Cazorla, Segura, Las Villas y Mágina & 60,0 & 17,8 & 6,7 & 6,7 & 8,9 & 45 \\
\hline & & Centro-Norte de Jaén & 42,9 & 11,4 & 5,7 & 28,6 & 11,4 & 35 \\
\hline & & Valle del Guadiato-Los Pedroches & 76,0 & & & 12,0 & 8,0 & 25 \\
\hline & & Sierra Norte de Sevilla & 64,3 & 14,3 & & 14,3 & 7,1 & 14 \\
\hline & & Sierra de Aracena & 51,7 & 17,2 & 3,4 & 10,3 & 13,8 & 29 \\
\hline & & Andévalo y Minas & 66,7 & 14,3 & & & 19,0 & 21 \\
\hline & \multirow{7}{*}{ 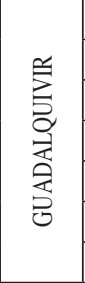 } & Montoso & 28,6 & 14,3 & 28,6 & & 28,6 & 7 \\
\hline & & Campiña y Subbético de Córdoba-Jaén & 33,3 & 16,7 & 2,8 & 25,0 & 22,2 & 36 \\
\hline & & Campiña y Sierra Sur de Sevilla & 14,7 & 14,7 & 5,9 & 35,3 & 26,5 & 34 \\
\hline & & Vega del Guadalquivir & 6,3 & 12,5 & 31,3 & 25,0 & 25,0 & 16 \\
\hline & & Bajo Guadalquivir & & 14,3 & 28,6 & 57,1 & & 7 \\
\hline & & Aljarafe-Condado-Marismas & 12,0 & 12,0 & 12,0 & 20,0 & 40,0 & 25 \\
\hline & & La Janda & & 28,6 & 14,3 & 42,9 & 14,3 & 7 \\
\hline & \multirow{2}{*}{ S.I. } & Altiplanicies Orientales & 61,7 & 21,7 & 3,3 & 3,3 & 8,3 & 60 \\
\hline & & Depresiones de Antequera y Granada & 28,2 & 17,9 & & 20,5 & 30,8 & 39 \\
\hline & \multirow{3}{*}{ 酱 } & Sureste árido-Almanzora & 27,7 & 44,7 & 6,4 & 4,3 & 17,0 & 47 \\
\hline & & Alpujarras-Sierra Nevada & 51,8 & 17,9 & 5,4 & 12,5 & 10,7 & 56 \\
\hline & & Serranías de Cádiz y Ronda & 39,2 & 21,6 & 3,9 & 23,5 & 9,8 & 51 \\
\hline \multirow{7}{*}{\multicolumn{2}{|c|}{ 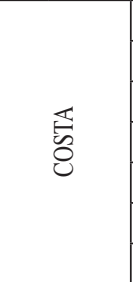 }} & Levante almeriense & & & & & 100,0 & 11 \\
\hline & & Poniente Almeriense & & 11,1 & & 22,2 & 66,7 & 9 \\
\hline & & Costa de Granada & 23,5 & 29,4 & & & 47,1 & 17 \\
\hline & & Vélez-Málaga y Axarquía & 10,3 & 44,8 & & 6,9 & 37,9 & 29 \\
\hline & & Costa del Sol & & & & & 100 & 9 \\
\hline & & Costa Noroeste de Cádiz & & & 25,0 & 75,0 & & 4 \\
\hline & & Costa Occidental de Huelva & & & & & 100,0 & 6 \\
\hline \multirow{9}{*}{\multicolumn{2}{|c|}{ 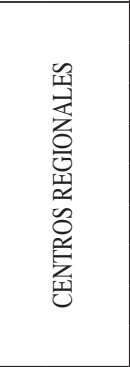 }} & C.R. de Almería & & & 12,5 & 50,0 & $37,5^{*}$ & 8 \\
\hline & & C.R. de Málaga & & $23,1^{*}$ & 7,7 & 38,5 & 30,8 & 13 \\
\hline & & C.R. de Bahía de Algeciras & & 14,3 & & 28,6 & $57,1^{*}$ & 7 \\
\hline & & C.R. de Bahía Cádiz-Jerez & $16,7^{*}$ & & $50,0^{*}$ & 33,3 & & 6 \\
\hline & & C.R. de Huelva & & & 25,0 & 50,0 & $25,0^{*}$ & 8 \\
\hline & & C.R. de Sevilla & $3,6^{*}$ & 10,7 & 60,7 & 25,0 & & 28 \\
\hline & & C.R. de Córdoba & 12,5 & & 50,0 & & $25,0^{*}$ & 8 \\
\hline & & C.R. de Granada & $4,9^{*}$ & 2,4 & 58,5 & 22,0 & 12,2 & 41 \\
\hline & & C.R. de Jaén & 8,3 & $16,7^{*}$ & 25,0 & 33,3 & 16,7 & 12 \\
\hline \multicolumn{3}{|c|}{ TOTAL MUNICIPIOS ANDALUCES } & 31,8 & 16,9 & 11,4 & 17,3 & 21,0 & 770 \\
\hline
\end{tabular}

Fuente: Padrón de habitantes (2004 y 2009). Elaboración Propia.

4 En las fila de los Centros Regionales, un asterisco identifica la casilla donde uno de los municipios registrados es la ciudad cabecera del centro correspondiente.

5 Tipo $1^{\circ}$ : Decrecen; aunque crecen los extranjeros; Tipo $2^{\circ}$ : Crecen; los extranjeros superan la pérdida de españoles. Tipo 3.1, 3.2 y 3.3: los extranjeros dan, respectivamente: $>20 \%$, del 20 al $50 \%$ o >50\% del crecimiento de la suma de ambos colectivos. 
Este acercamiento vuelve a mostrar las señas de identidad de los grandes ámbitos geográficos.

Se manifiesta como un rasgo común la identificación de las «unidades territoriales» agrupadas en el «Sector Montañoso Norte», con la situación de declive demográfico, a pesar del aumento del número de extranjeros. Salvo el Centro Norte de Jaén, de entidad geográfica muy diferente, que escapa en parte a este ámbito, todas han perdido algo de población. Tasas en general muy pequeñas. Y se aprecia igualmente que las pérdidas están muy suavizadas por el incremento de los extranjeros, de modo que éstos han amortiguado un declive que hubiera sido de una cuantía muy superior. La uniformidad interna en cada unidad es importante, pues más de la mitad de los municipios responden también al perfil general. Cabe destacar que en estas zonas montañosas escapan a ese abierto declive todos los municipios de 10.000 habitantes y más. Todos ellos crecen, algunos lo hacen a pesar de la disminución de los españoles, pero generalmente con ambos aportes y moderadamente. Es así que el efecto de los extranjeros no modifica esencialmente el declive demográfico, pero lo está amortiguando.

También ofrece un perfil relativamente bien definido el conjunto de «unidades territoriales» del Guadalquivir (excluidos sus Centros Regionales). En este caso el perfil dominante es el tipo tres: crecimiento combinado de los dos grupos, españoles y extranjeros. El modelo se repite en cada una de las «unidades territoriales» (solo difiere la de Montoro, por el descenso leve de la población española), pero la uniformidad no es tan completa. Las diferencias se cifran en la intensidad del crecimiento (que oscila entre el 3\%o de Montoro al casi 18\%o de la Vega del Guadalquivir) y en la participación en el mismo del grupo extranjero. En este sentido, la diferencia más acentuada por ser más importante el crecimiento de extranjeros que el de españoles corresponde a las «unidades territoriales» del Aljarafe (con un crecimiento importante) y la de la Campiña y Subbético de Córdoba-Jaén (una unidad del borde de la depresión, y especialización olivarera), que recuerda al resto de la montaña, con un crecimiento de los españoles modesto.

La uniformidad interna de las comarcas es también importante (entre el 50\% a más del $70 \%$ de los municipios, según unidades, responde al perfil del ámbito geográfico). Pero aunque sean poco numerosos en todas las unidades hay municipios que responden al tipo $2^{\circ}, \mathrm{o}$ al tipo $1^{\circ}$, que recuerdan el declive de la montaña norte; estos últimos se concentran esencialmente en dos de las «unidades territoriales»: Montoro y Campiña y Subbético de CórdobaJaén. Pero cabe destacar que en estas anomalías internas se advierte la incidencia del rango demográfico de los municipios. En el caso del Guadalquivir, los que más discrepan sobre el modelo medio son los municipios de menor población. Sirva de confirmación los dos datos siguientes: en los 40 municipios de menos de 5.000 habitantes de este ámbito territorial, se concentran la mayoría de los que están en declive (16 de 23) y la mitad de los que no pierden población gracias a la compensación de extranjeros (10 de 20).

Avanzando al interior de las Béticas, el papel del crecimiento de los extranjeros en el desenvolvimiento general se ve acentuado por el estancamiento o declive de la población española.

Sobre las dos unidades englobadas como «Surco Intrabético», las Altiplanicies Orientales ofrecen en estos años un declive (3.500 españoles menos), que se salda en una tasa de leve crecimiento, gracias al asentamiento de extranjeros. Pero esta compensación en la unidad territorial no existe en la mayoría de sus municipios, de modo que casi el $62 \%$ de ellos en 
realidad están en declive demográfico aunque aumentando su población extranjera. Sobre las depresiones de Granada y Antequera, la crisis no es tan manifiesta, pero en el modesto crecimiento más del $80 \%$ es debido al aumento de los extranjeros. A este modelo responden la totalidad de los pocos municipios de ambas unidades que superan los 10.000 habitantes, cabeceras de comarcas en general. En todos ellos el crecimiento se debe a extranjeros; en un caso (Guadix) junto al retroceso real de la española; en los otros (Baza, Íllora, Loja o Antequera, (tipo 3.3)) dando la mayor parte de los crecimientos.

La crisis demográfica que arrastran los municipios de la «Penibética», que ha ido afianzando el predomino característico en este espacio de los pequeños asentamientos de población (de 154 municipios, 85 se reducen a menos de 1.000 habitantes y solo 16 exceden los 5.000) pareció contenerse en los últimos años, al tiempo que aumentaba el asentamiento de los extranjeros. Relación que se confirma en los años observados: la población ha aumentado en 17.162 habitantes, de los cuales menos de 500 lo aportan españoles.

El papel del crecimiento de los extranjeros se acentúa de oeste a este, de modo que en el interior almeriense la unidad de Sureste árido-Almanzora muestra una de las situaciones más curiosas: un crecimiento apreciable (tasa media anual de 20,92 por mil), a pesar de que en el mismo periodo el declive de la población española se ha mantenido (-1.674 habitantes). A un tono de menor intensidad, se repite el modelo en la Alpujarra-Sierra Nevada. Consecuente con ello, un gran número de los municipios de la zona almeriense se han catalogado en el tipo $2^{\circ}$, es decir, crecen sin participación de españoles; mientras que en la granadina predominan los que pierden población a pesar de que aumenten los extranjeros (tipo $1^{\circ}$ ).

En el conjunto de las unidades penibéticas, la Serranía de Cádiz y Ronda parecen descolgarse del modelo medio y claramente de los otros dos sectores, almeriense y granadino, al experimentar un leve crecimiento propiciado por las dos nacionalidades. Este mayor equilibrio hace sospechar lo que realmente ocurre: las compensaciones de unos con otros municipios, debido al peso demográfico de núcleos como Arcos de la Frontera o Ronda, que efectivamente combinan los dos crecimientos. Por ese motivo esta unidad es más dispar en su interior: en cabeza van los municipios que reproducen el tipo $1^{\circ}$, en declive a pesar del aumento de los extranjeros; siguen en número los del tipo $2^{\circ}$, que crecen gracias únicamente a la aportación extranjera, los modelos que son dominantes en el conjunto del ámbito geográfico.

El agregado de «unidades territoriales» costeras, como cabía esperar, presenta rasgos muy definidos y particulares con relación al resto del territorio andaluz. Su crecimiento es el más elevado; está participado por el aumento de la población española (aumenta 67.536) y por el más abundante aún de población extranjera (139.831 habitantes). Es habitual pensar en el litoral como el espacio andaluz más dinámico. La evolución de estos años lo refrenda: 207.367 habitantes de crecimiento en el quinquenio, con tasas medias elevadas. La observación de los datos de cada unidad confirma el genérico dinamismo de este espacio y su atracción como asentamiento de extranjeros: en cada una de las unidades que la componen, a ellos se ha debido 2/3 o más del crecimiento. Sólo la costa Noroeste de Cádiz es más inmune a estos procesos.

La uniformidad interna es muy elevada. En tres de las unidades - Levante Almeriense, Costa del Sol y Costa Occidental de Huelva - la totalidad de sus municipios se ha identificado en el mismo tipo (3.3), crecimiento propiciado por los dos colectivos, pero con alto 
predominio de los extranjeros. El modelo como puede comprobarse en el cuadro 11 no es específico del sector costero. El valor añadido que en él incorpora, es que va asociado a tasas de crecimiento medio anual muy elevado, y presente en todo rango de poblaciones. Esta uniformidad interna no es tan completa en las unidades de Costa de Granada y Vélez-Málaga y Axarquía, pero se debe a que cabalgan en parte sobre la Penibética y algunos de sus municipios allí asentados reproducen el modelo de la montaña con declive de población española.

Por lo que respecta a los Centros Regionales, cabe unificarlos porque todos ganan población, pero difieren bastante en la intensidad: tasas medias de un 6 a 8 por mil señalan a los Centros Regionales de Jaén y Córdoba como los menos dinámicos en este periodo; las tasas más altas (de 18 a 20 por mil anual) las han experimentado Granada, Málaga y Almería. Entre estos extremos (tasas de 10 a 15 por mil) los restantes. Como se ve, son tasas más moderadas que las de la Costa. También difieren de la «Costa» y este sería su rasgo más peculiar como conjunto, por la participación más abundante de la población española en el crecimiento.

Merece subrayarse que en estas áreas urbanas se haya concentrado el 64\% del crecimiento de la población de nacionalidad española dentro de Andalucía (proporción que sobrepasa muy ampliamente su peso demográfico en la región). En concreto, su crecimiento se cifra en 165.113 españoles. Por ello, aunque es muy voluminoso el incremento de los extranjeros (143.540), su diferencia con las zonas costeras es inevitable: la aportación de los extranjeros al crecimiento en los Centros Regionales es proporcionalmente más moderada. En la mayoría oscila entre el 32 y el 50\%, márgenes de los que se descuelga Cádiz, con la proporción más baja (27\%) y que sólo rebasan los Centros Regionales de Málaga y Almería en continuidad de carácter con el resto de la costa mediterránea andaluza.

Puede subrayarse como el rasgo más característico de los Centros Regionales este mayor dinamismo de la población española, que naturalmente relacionamos con la fuerza de la atracción residencial de los entornos urbanos. Esta circunstancia se convierte a su vez en un motivo de heterogeneidad interna dentro de las grandes áreas urbanas; en concreto, en un contraste generalizado entre las ciudades que originan la aglomeración y el resto de los municipios, de acuerdo a cómo ha ido progresando la difusión de la ciudad y las consecuentes evoluciones de la movilidad residencial dentro de las propias áreas urbanas.

En tasas de crecimiento se comprueba una discordancia genérica entre el mayor dinamismo del resto del área urbana que el de la ciudad que la origina. Estas ofrecen crecimientos relativos más atenuados, cuando no inexistentes, y por lo que a la participación extranjera respecta, el hecho esencial es que en las capitales los crecimientos se deben casi en exclusiva a la población extranjera (Cuadro 13).

Así pues, el crecimiento de la población española en los Centros Regionales no se ubica sobre las capitales. Sólo en tres de ellas los españoles han aumentado en valores modestos y siempre por debajo del aumento de los extranjeros; y en cinco de las ocho capitales han ido en descenso y en varios casos, como Granada y Sevilla, con valores nada despreciables. De modo que en ellas el aumento de los extranjeros ha reportado lo esencial del crecimiento o ha amortiguado el declive a que le arrastraría la población española, progresivamente más envejecida y/o despoblada a favor de sus áreas urbanas. 
Cuadro 13

COMPOSICIÓN POR NACIONALIDAD DEL CRECIMIENTO DE LAS CAPITALES ANDALUZAS

\begin{tabular}{|l|r|r|r|}
\hline & \multicolumn{3}{|c|}{ Crecimiento en el quinquenio 2004-2009 } \\
\hline & Total Población & \multicolumn{1}{c|}{ Extranjeros } & \multicolumn{2}{c|}{ Españoles } \\
\hline Almería & 11.125 & 9.087 & 2.042 \\
\hline Cádiz & -6.479 & 973 & -7.449 \\
\hline Córdoba & 8.736 & 4.954 & 3.782 \\
\hline Granada & -3.967 & 5.489 & -9.465 \\
\hline Hueva & 4.437 & 4.133 & 304 \\
\hline Jaén & 640 & 1.391 & -750 \\
\hline Málaga & 20.574 & 21.568 & -994 \\
\hline Sevilla & -997 & 18.126 & -19.123 \\
\hline Total capitales & 34.069 & 65.721 & -31.653 \\
\hline
\end{tabular}

Fuente: Padrón de habitantes (2004 y 2009). Elaboración Propia.

Es un hecho que merece ser subrayado porque hace relación a la forma en que la vivienda reconduce la localización de la inmigración atraída por los aglomerados urbanos mayores. Refleja, a trazos generales, una de las tendencias más significativas de la distribución de los extranjeros en los medios urbanos: la de aglomerase espacialmente en aquellas áreas de la ciudad que venían perdiendo población, encajando en el proceso de cambio social de las áreas urbanas asociado a la vida de la vivienda o a su cadena de vacantes. El tema pertenece a otra escala de análisis, pero es evocador para concluir que, en definitiva, su presencia en ciertos barrios de las ciudades, como en algunas zonas de montaña, resulta repobladora.

\section{CONCLUSIONES}

Con relación al objetivo global que abordó la investigación, los datos aportados permiten confirmar que, a pesar de la extensión y desigualdad territorial de Andalucía, la mayor parte de su territorio se ha visto alcanzado por el efecto de la inmigración extranjera. En segundo lugar, respecto a su incidencia en el crecimiento local o en las estructuras demográficas de poblaciones de áreas y localidades tan dispares geográficamente, han confirmado un cuadro de contrastes de gran interés geográfico.

La primera conclusión es que el fenómeno alcanza una difusión espacial que no se justificaría por el dinamismo económico. El análisis ha mostrado un complejo patrón en la distribución territorial de los extranjeros en Andalucía, que hace evidente la variedad de factores de atracción que se conjugan en la región y su relación con la existencia de dos modelos de inmigrantes (trabajadores y «residenciales»). Las recientes oleadas de trabajadores siguen normalmente al mercado de trabajo, por ello los niveles de actividad de la costa y los centros urbanos explican las principales concentraciones (que en las primeras se suman a los de residentes turísticos dando las tasas más elevadas); pero también los vacíos de trabajadores 
dejados por la emigración justifican su difusión hacia pequeñas localidades de poca actividad que, al añadirse a la difusión hacia la montaña que va experimentando la urbanización turística, amplían la difusión espacial del fenómeno inmigratorio más allá de lo que la dinámica económica explicaría.

Por lo que respecta a los efectos sobre las estructuras demográficas, cabe concluir que aunque se muestra un cuadro de disparidades elevadas, su explicación tiene una gran coherencia con el patrón de distribución. La clave de las diferencias reside en el contraste de áreas dinámicas o de áreas en declive como zonas de asentamientos, y su relación con las diferencias demográficas de los grupos extranjeros, asociadas a sus modelos migratorios. Respecto a ellas, la principal se deriva del predominio de los residentes europeos frente a los trabajadores del sur y del este. Tal circunstancia que diferencia claramente al sector costero (con zonas de la montaña inmediata), frente al resto de los ámbitos subregionales, deja su huella en los efectos sobre la edad. En segundo lugar, la diferente composición de la inmigración trabajadora (que a nivel general está muy relacionada con los grupos de origen) se manifiesta con diferencias espaciales muy vinculadas a las ocupaciones locales. Así, los servicios en las zonas urbanas y turísticas, y las agriculturas forzadas en el litoral almeriense, por la mayor feminización de los asentados en las primeras y la juventud y masculinización de los extranjeros en la segunda, justifica igualmente las diferencias más notorias respecto a la media regional en la incidencia sobre la sex ratio además de en la edad.

Finalmente, en relación a la incidencia demográfica más visible, el efecto sobre el crecimiento real, el análisis de su composición, entre españoles y extranjeros, ha permitido concluir no ya la positiva incidencia en la población andaluza, o el impulso al crecimiento en algunas áreas de claro dinamismo, sino esencialmente el efecto de contención que por el momento está significando en el declive demográfico de muchos ámbitos rurales, especialmente de zonas montañosas. Observado a nivel de localidades, el efecto compensador del declive de la población española que no alcanza a la zona montañosa norte, se deja sentir, sin embargo, en sus localidades mayores; mientras en la montaña bética (sobre todo en el más despoblado sector árido) está conteniendo el declive de localidades de cualquier rango, con un efectivo aunque débil efecto repoblador. Efecto similar tiene en las capitales provinciales, en las que los extranjeros han mitigado o interrumpido el declive demográfico al que le conduce el descenso de la población española, envejecida y mermada por la atracción residencial de las áreas periurbanas.

\section{BIBLIOGRAFÍA}

AA.VV. (1998): «La población en Andalucía». Boletín Económico de Andalucía, no 24 , (número monográfico).

ARANGO, VILLA-BELDA J. (2004): «La inmigración en España a comienzos del siglo XXI», en LEAL, J. (coord.). Informe sobre la situación demográfica en España, 384.

ARROYO PÉREZ, A., CALOT, G., FERNÁNDEZ CORDÓN, J.A. (1998): Un siglo de demografía de Andalucía. La población desde 1990. Sevilla. IEA.

BAYONA J, GIL ALONSO, F. (2008): «El papel de la inmigración extranjera en la expansión de las áreas urbanas. El caso de Barcelona (1998-2007)». Scripta Nova, nº 270.

CÁRDENAS RODRÍGUEZ, R., MONREAL GUERRERO, C. (2008): «La inmigración femenina en España». Revista de Humanidades, $\mathrm{n}^{\circ}$ 15, 115-138. 
CARVAJAL GUTIÉRREZ, M.C. (2009): «Efecto de las migraciones en la estructura por edad y sexo de la áreas residenciales», en LÓPEZ TRIGAL, L., ABELLÁN GARCÍA, A., DIRK GODENAU: Despoblación, envejecimiento y territorio. Un análisis sobre la población española. Universidad de León, 125-136.

CARVAJAL GUTIÉRRREZ, C. (1993): «Tipificación de los municipios andaluces por sus recursos humanos». Baetica, $\mathrm{n}^{\circ}$ 15, 53-64.

CASTLES, S., MILLER, M. (2009): La edad de la migración: movimientos internacionales de población en el mundo moderno, 4 a edición, Macmillan Press LTD, 336.

CATARINO, C., OSO, L. (2000): «La inmigración femenina en Madrid y Lisboa: hacia una etnización del servicio doméstico y de las empresas de limpieza». Papers, $\mathrm{n}^{\circ}$ 60, 183-202.

COLLATE, F. (2006): «El declive demográfico de la montaña española 1860-2000. ¿Un drama rural?». Revista de estudios sobre despoblación y desarrollo rural, $\mathrm{n}^{\circ}$ 5, 159-162.

DE MIGUEL CASTAÑO, C. (2005). «Inmigración, demografía y mercado laboral». Economistas, $\mathrm{n}^{\circ} 104,207-213$.

EGEA JIMÉNEZ, C. (2005): «La inmigración actual en Andalucía (1997-2001)». Geo Crítica Scripta Nova, Revista electrónica de geografía y ciencias sociales, $\mathrm{n}^{\circ} 192$.

FERNÁNDEZ CORDÓN, J.A. (2006): Análisis territorial de la demografía española. Fundación Fernando Abril Martorell, 537.

FERNÁNDEZ CORDÓN, J.A. (2004): «Demografía e inmigración». Economista, nº 22 (99), 16-27.

FERNÁNDEZ CORDÓN, J.A. (2009). «Diez años que sacudieron la demografía española». Cuadernos de Información Económica, nº 208, 187-196.

FERNÁNDEZ SALINAS, V. (2001): «Las tendencias demográficas recientes de la población andaluza». Eria, n $^{\circ}$ 54-55, 77-93.

FERRER REGAÑES, M. (2005): «Inmigración, integración y cambio urbano y rural», Empresa y Humanismo, vol. 9, $\mathrm{n}^{\circ}$ 1, 67-100.

FULLAONDO, A. (2007): «La inmigración en España: una aproximación metropolitana comparada». ACE (Arquitectura, Ciudad y Entorno), no 4, 497-514.

GARCÍA CASTAÑO, J, GRANADOS MARTÍNEZ, A. (2002): «La inmigración extranjera en Andalucía» en MOYANO ESTRADA, E., PÉREZ IRUELA, M. La sociedad andaluza. Córdoba, Instituto de Estudios de Andalucía, 651-685.

GONZÁLEZ, J., REQUENA, M. (2005): Tres décadas de cambio social en España. Madrid, Alianza, 390.

GORDO MÁRQUEZ, M. (2002): Mercado de trabajo agrícola e inmigración extranjera en la provincia de Huelva. Dirección general de coordinación de política migratoria. II seminario sobre investigación de la inmigración extranjera en Andalucía. Sevilla.

INSTITUTO DE ESTADÍSTICA DE ANDALUCÍA (2002): Inmigración extranjera en Andalucía. IEA. Junta de Andalucía.

IZCARA PALACIOS, S. P., GARCÍA SANZ B. (2003): Los trabajadores inmigrantes en la agricultura. Papeles de Economía Española, ${ }^{\circ}$ 98, 109-120.

IZQUIERDO ESCRIBANO, A. (dir.) (2003): Inmigración, mercado de trabajo protección social. Consejo Económico y Social, CES. Colección Estudio, Madrid, 330.

IZQUIERDO ESCRIBANO, A., LÓPEZ DE LARA, D. (2003): «El rastro demográfico de la inmigración en España: 1996-2002». Papeles de Economía Española, nº 98, 68-93. 
JIMENO SERRANO, J.F. (2009): «El impacto laboral de la inmigración en España: nuevos resultados empíricos». Principios $\mathrm{n}^{\circ} 15,5-9$.

LARRUBIA VARGAS, R., OCAÑA OCAÑA, M. (2011): «Extranjeros en Andalucía. Diversificación de las corrientes inmigratorias y sus patrones de distribución sobre el espacio andaluz» artículo enviado a ERIA, junio, 2011.

LÓPEZ DE LERA, D. (1995): «La inmigración en España a finales del S. XX. Los que vienen a trabajar y los que vienen a descansar». Reís $n^{\circ}$ 71-72, 225-245.

LÓPEZ DE LERA, D. (2006): «El impacto de la inmigración extranjera en las regiones españolas» en LEAL, J., FERNÁNDEZ CORDÓN (Coord.). Análisis territorial de la demografía española, 537.

MARCU, S. (2009): «Inmigrantes rumanas en el servicio doméstico y de cuidados de la Comunidad de Madrid. Estudio cualitativo». Estudios Geográficos no 267, 463-489.

MARTÍNEZ CHICO, R. (2004): Inmigración extranjera y trabajo. Temporeros extranjeros en la recogida de la aceituna de Jaén. Consejo económico y social de la provincia de Jaén.

MAZÓN T., ALEDO, (2005): Turismo residencial y cambio social. Nuevas perspectivas teóricas y empíricas. Alicante, Editorial Aguaclara.

NIETO CALMAESTRA, J.A. (2002): «Inmigración extranjera en Andalucía. Análisis demográfico» en GARCÍA CASTAÑO, MURIEL LÓPEZ (Ed.): La inmigración en España. Tercer Congreso de estudios interculturales, Universidad de Granada, 11.

NIETO CALMAESTRO, A., EGEA JIMÉNEZ, C. (2005). «La dinámica demográfica en Andalucía en el último cuarto del S. S XX.». Cuadernos Geográficos, nº 36, 125-151.

OCAÑA OCAÑA, C., GARCÍA MANRIQUE, E., NAVARRO RODRÍGUEZ, S.R. (1999): Andalucía, población y espacio rural. Consejería de Agricultura y Pesca. Junta de Andalucía, 599.

OLIVERA HERRERA, A., ANCHUELO CREGO, A.L. (2005): «Factores demográficos en los flujos migratorios entre la Europa del Este y la UE-15». Papeles de Economía Española, $n^{\circ} 103,202-2015$.

POZO RIVERA, E., GARCÍA PALOMARES J.C. (2009): «Inmigración y cambio demográfico en la región metropolitana madrileña (1996-2006)». Anales de Geografía, nº 1, 111-138.

RAYA MELLADO, P. (Dir.) (2001): Turismo residencial en Andalucía. Sevilla, Consejería de Turismo y Deporte. Junta de Andalucía.

RECAÑO VALVERDE, J. (2004): «La transición migratoria en España durante el S. XX». VII Congreso de la ADEH, Granada.

RECHER, F., REQUENA, M (Eds) (2009): Las múltiples caras de la emigración en España. Madrid, Alianza, 325.

SÁNCHEZ FERNÁNDEZ, J. (1999): «Evolución de la dinámica espacial de la población andaluza». Revista de Estudios Regionales, $\mathrm{n}^{\circ}$ 54, 359-380.

SEMPERE SOUVANNAVONG, J.D. (2002): «Marroquíes y ecuatorianos en la agricultura intensiva del litoral mediterráneo». Cuadernos de Geografía, n 72, 173-190, Valencia.

URDIALES VIEDAMA, M.E., MENÉNDEZ COLLATES, M. (2005): «La población extranjera en Andalucía». Cuadernos Geográficos, nº 36, 169-184

VALERO ESCANDELL, J. (2006): «Las inmigraciones internacionales: motor de cambios sociodemográficos y territoriales». Ponencia presentada al X Congreso de la Población Española. Pamplona, 29 de junio - 1 de julio, 2006. 